\title{
Engineering model for intumescent coating behavior in a pilot-scale gas-fired furnace
}

\author{
Nørgaard, Kristian Petersen; Dam-Johansen, Kim; Català, Pere; Kiil, Søren
}

Published in:

AIChE Journal

Link to article, DOI:

10.1002/aic.15291

Publication date:

2016

Document Version

Peer reviewed version

Link back to DTU Orbit

Citation (APA):

Nørgaard, K. P., Dam-Johansen, K., Català, P., \& Kiil, S. (2016). Engineering model for intumescent coating behavior in a pilot-scale gas-fired furnace. AlChE Journal, 62(11), 3947-3962 . https://doi.org/10.1002/aic.15291

\section{General rights}

Copyright and moral rights for the publications made accessible in the public portal are retained by the authors and/or other copyright owners and it is a condition of accessing publications that users recognise and abide by the legal requirements associated with these rights.

- Users may download and print one copy of any publication from the public portal for the purpose of private study or research.

- You may not further distribute the material or use it for any profit-making activity or commercial gain

- You may freely distribute the URL identifying the publication in the public portal

If you believe that this document breaches copyright please contact us providing details, and we will remove access to the work immediately and investigate your claim. 


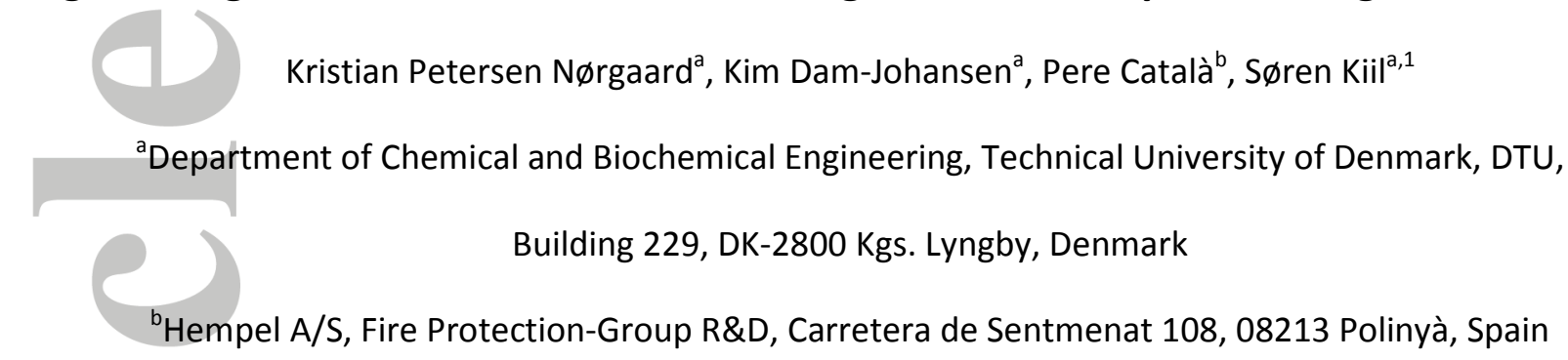

\section{Abstract}

In the event of a fire, intumescent fire protective coatings expand and form a thermally insulating char that protects the underlying substrate from heat and subsequent structural failure. The intumescence includes several rate phenomena, which have been investigated and quantified in the literature for several decades. However, various challenges still exist. The most important one concerns mathematical model validation under realistic exposure conditions and/or time scales. Another is the simplification of advanced models to overcome the often-seen lack of a complete set of input and adjustable model parameters for a given coating, thereby providing models for industrial applications. In this work, these two challenges are addressed. Three experimental series, with an intumescent coating inside a $0.65 \mathrm{~m}^{3}$ gas-fired furnace, heating up according to so-called cellulosic fire conditions, were conducted and a very good repeatability was evident. The experiments were run for almost three hours, reaching a final gas temperature of about $1100{ }^{\circ} \mathrm{C}$. Measurements include transient temperature developments inside the expanding char, at the steel substrate, and in the mineral wool insulation placed behind the substrate. A mathematical model, describing the intumescent coating behavior and temperatures in the furnace using a single overall reaction was developed and validated against experimental data. By including a decomposition front movement through the char, a good qualitative agreement was obtained. After further validation against experiments with other coating formulations, it has potential to become a practical engineering tool.

Keywords: Intumescent coatings, modeling, fire tests, intumescent model validation

${ }^{1}$ Corresponding author. Telephone: 45452528 27. Fax: 45-45882258. E-mail: sk@kt.dtu.dk.

This article has been accepted for publication and undergone full peer review but has not been through the copyediting, typesetting, pagination and proofreading process which may lead to differences between this version and the Version of Record. Please cite this article as doi: 10.1002/aic.15291 (c) 2016 American Institute of Chemical Engineers (AIChE) 


\section{Introduction}

If a fire occurs, intumescent fire-protective coatings undergo a complex reaction sequence, which results in a thick, thermally insulating char on top of the substrate (e.g. steel). The char prolongs the time before a steel structure reaches a critical temperature and collapses ${ }^{1-3}$. In general, intumescent coatings expand according to a series of steps, which begins with melting and degradation of the polymer matrix, followed by decomposition of gas-releasing compounds and char formation, and finally, at high temperatures, char degradation ${ }^{4}$. A detailed description of the chemistry and physics of the various steps in the intumescent char formation process can be found in earlier work ${ }^{5}$.

An important challenge in intumescent coatings development is the requirements for expensive and time consuming-third party approval tests, which must take place prior to a new coating being marketed. To improve fire safety, mapping the influence of furnace process parameters, and optimize coatings for approval tests, a fundamental understanding of the underlying intumescent process mechanisms is of great interest. To provide such understanding, mathematical models are useful and many modeling activities have taken place as described in three important review articles ${ }^{2,4,6}$. In short, the mathematical models developed are typically validated against experimental data obtained in well-controlled, small-scale laboratory equipment (e.g., cone calorimeters), where conditions like gas flows or heating rates can differ substantially from those present in real fire conditions. In addition, the models developed are often of a very high complexity (partial differential equations), requiring a large number of input and adjustable parameters (e.g. melt viscosities of the binder phase and a set of rate constants), which may be tedious and/or time-consuming to measure or validate for new coating systems or process conditions. While the advanced models can certainly help to map the phenomena involved, their practical use may be somewhat limited.

The aim of the present work was to obtain several experimental data series for an intumescent coating exposed in a pilot-scale, natural-gas-fired furnace. Additionally, a mathematical model, containing only the most important rate phenomena, is developed. The model can simulate transient developments in char and 
steel temperatures, as well as expansion-time curves of an intumescent coating. Model simulations are compared to the pilot-scale furnace measurements, and suggestions are provided for how to use the model in daily work with coating optimization and process development.

\section{Validation methods for previous models of intumescent coatings}

A number of models on intumescent coatings are available in the literature and have been reviewed by several authors $^{2,4,6}$. The models range from classical mathematical models ${ }^{2,4,7}$, considering factors such as heat conduction, expansion and gas production, to more empirical models ${ }^{8-10}$, in which a set of experimental data, obtained in laboratory-scale equipment, is used to rank performance of different coating formulations for fullscale tests. In 2010, Griffin ${ }^{6}$ identified five main limitations to the current models before these can be applied to real-world situations. The limitations are: 1) models are only in 1D, 2) complete data for a particular coating system are not available, 3) effects of radiation and turbulent gasses, present in large-scale furnace tests and difficult to mimic in small-scale laboratory equipment, are not included in current models, 4) the use of an expansion factor based on the post-heated char thickness is often used, and 5) studies on the effect of variations in oxygen content are limited. It is noted by Griffin that multidimensional models are of particular interest when simulating the behavior of coatings applied to complex geometries used in many types of constructions. Shi and $\mathrm{Chew}^{4}$ identified a lack of models dealing with the mechanical behavior of intumescent coatings under external loads (not specified further) and also a need for modeling of toxic gasses produced in the coating during a fire. Furthermore, modeling of expansion of intumescent coatings is complicated by the often-seen irregular expansion behavior ${ }^{4}$. Shi and $\mathrm{Chew}^{4}$ provide a table of input parameters taking into account different models of intumescent coatings. Parameters related to heat conduction, pyrolysis, transport of gas volatiles, coating/char volume change, internal gas pressure, water evaporation, gas permeability, porosity of the char, and mechanical behaviors are often included in the complex models. 
In Table 1, some details of the most recent models in the literature have been listed with respect to the experimental methods used for the validation of the models and the experimental times used in the experiments. Note that several of the models presented in the table focus on modeling of laminates, ablative coatings, or composites and not traditional intumescent coatings. Further details regarding the models can be found in Shi and $\mathrm{Chew}^{4}$. The table shows that validation of the models were done with laboratory equipment and over relatively short experimental times. Other relevant models can be found regarding intumescent coatings ${ }^{11-13}$. The articles by Mamleev et al. ${ }^{13}$ and Bourbigot et al. ${ }^{14}$ are particular interesting in that they used thermocouples, drilled through a steel substrate, to measure the temperature inside an expanding intumescent coating, placed below a gas burner or in the so-called lower oxygen index test. In the work by Mamleev et al. ${ }^{13}$, the temperatures were measured for 60 minutes and validation of the model performed using measurements at different positions inside the char. The modeling focused mostly on the viscosity of the coating during the intumescent process and included phenomena such as foam drainage and char shrinkage. However, as noted by Griffin ${ }^{6}$, the model shows poor agreement between experimental and modeled temperatures and the substrate temperature only reached $200^{\circ} \mathrm{C}$ during the experiment (as opposed to $800^{\circ} \mathrm{C}$ under more realistic conditions, see later). In the work of Bourbigot et al. ${ }^{14}$, the experimentation time was only $200 \mathrm{~s}$ (as opposed to the ISO834 cellulosic fire curve running over three hours) and lower exposure temperatures were used. The char expansion was simulated, but not compared to experimental data.

\section{Experimental procedures}

\section{Materials and sample preparation}

A generic solvent-borne acrylic intumescent coating, intended for protection against so-called cellulosic fires, has been used for this study. Besides binder and solvent, the coating contains the usual intumescent compounds, i.e. blowing agent (e.g. melamine), carbon source (e.g. pentaerythritol), acid source (e.g. ammonium polyphosphate), and pigments (e.g. $\mathrm{TiO}_{2}$ ). The coating was sprayed onto $\mathrm{C} 16$ steel substrate of 
dimensions $200 \times 300 \times 6 \mathrm{~mm}^{3}$. Prior to spraying of the intumescent coating, the steel substrate was coated with a commercial epoxy primer. The re-coating interval was at least 1 month, and the coating was sprayed onto the large face of the steel substrate using an airless spray with a tip 419. The dry coating thicknesses aimed at were approximately 1.2 and $2 \mathrm{~mm}$, but some variation cannot be avoided, due to the spray application and deformation during drying of the coating. The substrates were allowed to dry for at least two weeks. After drying, and just before the fire tests, coating thicknesses were measured using an Elcometer 456 TOP F1. Depending on the coating thickness, appropriate probes, either in the range of 0-1500 or 0-5000 $\mu \mathrm{m}$, were applied for the readings. The thicknesses for the two $1200 \mu \mathrm{m}$ experiments were measured in 9 different places on the individual substrates and found to be $1199 \pm 46$ and $1171 \pm 47 \mu \mathrm{m}$ and for the $2000 \mu \mathrm{m}$ cases $1969 \pm 67$ and $1948 \pm 99 \mu \mathrm{m}$. Experiments with uncoated steel were also performed.

\section{Gas-fired furnace}

A photo of the custom-build furnace, with important inner dimensions, is seen in Figure 1 . The steel substrate with intumescent coating was placed in a vertical position inside a frame in the wall of the gas-fired furnace, opposite to the viewing port and parallel to the gas flow. On the back side of the steel substrate, $8 \mathrm{~cm}$ of Superwool ${ }^{\circledR}$ mineral insulation is present. The temperature of the furnace is controlled by a thermocouple in front of the steel substrate and follows the ISO834 temperature-time curve, valid for cellulosic intumescent coatings. The gas to air ratio was 1:10 and the natural gas consumption approximately $13 \mathrm{~m}^{3}$ per hour at STP, thereby corresponding to a linear approximate velocity of $0.6 \mathrm{~m} / \mathrm{s}$, falling in the laminar regime.

Three types of experiments are used for the investigation and each experiment was run twice:

1. Steel substrate with coating thicknesses of approximately $1200 \mu \mathrm{m}$. Thermocouples are drilled through the steel substrate and positioned in steps of $1 \mathrm{~cm}$ above the coating.

2. Steel substrate with coating thicknesses of approximately $2000 \mu \mathrm{m}$. Thermocouples arranged as described under 1. 
3. Uncoated steel substrates also with thermocouples placed as described above. These experiments were used as reference to help evaluating expansion rates by comparing results for coated and uncoated steel substrates and thermocouples drilled through the steel plate. The heat transfer coefficient of the furnace was also determined from these experiments (more on this later).

The heating conditions and furnace differ, but it is noted that the thermocouple methodologies of Mamleev et al. ${ }^{13}$ and Bourbigot et al. ${ }^{14}$ have been important inspirations for the experiments of this work.

\section{Thermocouples and expansion measurements in gas-fired furnace}

A drawing of the experimental system in one dimension is seen in Figure 2, where temperatures measured (denoted Th\#) are indicated. In addition to the thermocouples shown, some thermocouples were placed at a greater distance from the coating, to measure the gas temperature. However, due to the response time of the thermocouples, these cannot not give a reliable gas temperature reading in the beginning of the experiments, where the temperature gradients are very steep. The set point temperature $\left(T h_{\text {set }}\right)$ is measured by a thermocouple in a shielding ceramic cover. K-type thermocouples with a junction diameter of $1.5 \mathrm{~mm}$ were used to measure the temperatures. The high junction diameter was selected for better endurance at the high temperatures in the furnace ${ }^{15}$, and new thermocouples were used for each test run. The thermocouples were either drilled $3 \mathrm{~mm}$ into the backside of the steel substrate or drilled through the steel substrate and positioned for every centimeter. A thermocouple was also used to measure the temperatures inside the backside insulation, $6 \mathrm{~cm}$ behind the steel substrate. The char expansion rate was measured by observing when the temperatures of the thermocouples drilled through the steel substrate began to deviate strongly from the temperatures measured with the uncoated steel substrates. The steel substrate is only coated on one side and heat can potentially flow to the steel substrate from the sides. To avoid this, a stone frame was inserted which partly covers the steel substrate, as shown in Figure 2. It is noted that the experiments, for reasons of understanding the behavior, were run for longer times than would normally be the case in a test series. Experiments were halted when the steel substrate temperature reached $550{ }^{\circ} \mathrm{C}$. 


\section{Mathematical modeling}

A mathematical model describing the behavior of an intumescent coating exposed to heating in a pilot-scale

furnace is now presented. A schematic drawing, is provided in Figure 3 showing the physical system, with indications of temperatures and thicknesses used for the model derivation. A single overall reaction is included to describe the char expansion. This reaction represents all phenomena in the expansion process including acid formation, char formation, decomposition of the blowing agent, and melting of the binder. Char degradation and oxidation, setting in at high temperatures, are described by a separate reaction mechanism.

Assumptions underlying the model development

- The intumescent coating contains blowing agent, binder, acid source, carbon source and pigments.

- Slab geometry only is considered.

- Heat transfer takes place in one dimension only.

- Heat transfer from gas to char surface is governed by convection only. Radiation from walls and gas to the coating is neglected.

- The heat transfer coefficient can be determined from experiments with uncoated steel.

- The steel substrate and backside insulation are chemically inert at all temperatures.

- Shrinkage of the expanded char is neglected.

- The expansion of the char layer can be described by a single chemical reaction, first order in the solids concentration.

- The rate of reaction for the expansion is evaluated at the temperature of the steel substrate (i.e. the expansion develops from the position of the original non-expanded coating).

- The chemical reaction of the solid coating is irreversible.

- Convective heat transfer inside the char pores is neglected.

- The char is considered intact at all times (i.e. no cracks in the surface). 
- The gas pressure inside the char is equal to ambient pressure, and the thermal conductivity of the gas only depends on temperature.

- The steel substrate is isothermal at all times.

- Heat effects from the char expansion reaction are neglected.

- During intumescence the entire coating is transformed into char (i.e., a single solids conversion value, $X$, is used and when $X=1$, full expansion is established).

- The porosity and density of the char formed attain constant temperature-independent values.

- A front moves through the char according to a decomposition reaction followed by oxidation at temperatures of $600{ }^{\circ} \mathrm{C}$. This front is referred to as the "decomposition front".

- Behind the decomposition front, the only solid present is $\mathrm{TiP}_{2} \mathrm{O}_{7}$.

- The thermal char properties on each side of the decomposition front can be slightly different (more on this later).

When describing the model development, three terms for the expanded coatings are used. "Char" refers to the expanded coating irrespectively of the thickness of the decomposed zone. "Residue" refers to oxidized char (present only in the decomposed zone) and "carbonaceous char" refers to char where carbon has not been oxidized. This is shown in Figure 3 and the separation between residue and carbonaceous char is defined by the decomposition front position.

Note that the model cannot be used for simulation of coating behavior in so-called cone calorimeters, which are based on heating by radiative heat transfer only, without modification. The model was developed for cellulosic coatings in a gas-fired furnace only.

\section{Char expansion}

The current char thickness, $\delta_{\text {char }}$, is described using the solids conversion, $\mathrm{X}$, and the maximum

expansion, $\delta_{\text {char,final, }}$ (measured after cooling of the expanded char)

$$
\delta_{\text {char }}=\mathrm{X} \cdot \delta_{\text {char,final }}+\delta_{0}
$$


where $\delta_{0}$ is the initial intumescent coating thickness.

The solids conversion is described by the following first-order reaction

$$
\frac{d \mathrm{X}}{d \mathrm{t}}=\mathrm{k}_{\mathrm{r}}(\mathrm{T}) \cdot(1-\mathrm{X})
$$

where $k_{r}(T)$ is a rate constant.

The initial condition is

$$
X(t=0)=0
$$

\section{Energy balance}

An energy balance of the steel plate, modeled as a thermal resistor network, gives

$$
\begin{gathered}
\rho_{\text {ste }} \cdot \mathrm{C}_{\mathrm{p}, \text { ste }}(\mathrm{T}) \cdot \delta_{\text {ste }} \frac{\partial \mathrm{T}_{\text {ste }}}{\partial \mathrm{t}} \\
\frac{1}{\frac{1}{\mathrm{~h}}+\frac{\delta_{\text {front }}(\mathrm{t})}{\mathrm{k}_{\text {residue }}(\mathrm{T})}+\frac{\delta_{\text {char }}(\mathrm{t})-\delta_{\text {front }}(\mathrm{t})}{\mathrm{k}_{\text {carb,char }}(\mathrm{T})}}\left(\mathrm{T}_{\text {gas }}-\mathrm{T}_{\text {ste }}\right)-\frac{\mathrm{k}_{\text {ins }}(\mathrm{T})}{\delta_{\text {ins }}}\left(\mathrm{T}_{\text {ste }}-\mathrm{T}_{\text {backside }}\right)
\end{gathered}
$$

where $\rho_{\text {ste }}$ is the density of steel, $C_{p, \text { ste }}$ is the heat capacity of steel, $\delta_{\text {ste }}$ is the thickness of the steel plate, $h$ is the heat transfer coefficient, $\delta_{\text {front }}$ is the thickness of the decomposed zone, $\mathrm{k}_{\text {residue }}$ is the thermal conductivity of the oxidized residue, and $\mathrm{k}_{\mathrm{carb} \text {,char }}$ is the thermal conductivity of the carbonaceous char. $\mathrm{T}$ is temperature and $\mathrm{t}$ is time. The thicknesses and temperatures are illustrated in Figure 3.

The initial condition is

$$
\mathrm{T}(l, \mathrm{t}=0)=\mathrm{T}_{\text {ste }, 0}
$$

The gas temperature, $\mathrm{T}_{\text {gas }}$, of the furnace is a model input parameter and $\mathrm{T}_{\text {backside }}$ is assumed constant at $25^{\circ} \mathrm{C}$.

Decomposition front 
Based on the experimental results that are presented in a later paragraph, a decomposition front moving through the char is included in the model. The front movement is initiated at a temperature of $600{ }^{\circ} \mathrm{C}$, and the mechanism is assumed to be solid decomposition followed by oxidation. The decomposition reaction is assumed to be the first step of titanium pyrophosphate formation, where the phosphorous ester decomposes to polyphosphoric acid, methane and carbon ${ }^{5,16}$

$$
\mathrm{C}_{10} \mathrm{H}_{10} \mathrm{O}_{6} \mathrm{P}_{2}(\mathrm{~s}) \rightarrow 2 \mathrm{HPO}_{3}\left(\mathrm{~s} \text { or I) }+2 \mathrm{CH}_{4}(\mathrm{~g})+8 \mathrm{C}(\mathrm{s})\right.
$$

In the second step, units of polyphosphoric acid react with $\mathrm{TiO}_{2}$ and form the white solid titanium

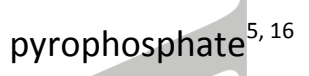

$$
2 \mathrm{HPO}_{3}(\mathrm{~s} \text { or I })+\mathrm{TiO}_{2}(\mathrm{~s}) \rightarrow \mathrm{TiP}_{2} \mathrm{O}_{7}(\mathrm{~s})+\mathrm{H}_{2} \mathrm{O}(\mathrm{g})
$$

Meanwhile, oxidation of methane and carbon occurs

$$
\mathrm{CH}_{4}(\mathrm{~g})+4 \mathrm{C}(\mathrm{s})+6 \mathrm{O}_{2}(\mathrm{~g}) \rightarrow 5 \mathrm{CO}_{2}(\mathrm{~g})+2 \mathrm{H}_{2} \mathrm{O}(\mathrm{g})
$$

The reaction shown in (6) is a solid decomposition where a solid transforms into gaseous and solid product(s).

Such reactions are known to proceed according to a growth of nucleii where the product phases are formed at reactive points in the original solid phase ${ }^{17}$. The solid decomposition is assumed to follow an S-shaped (sigmoidal) conversion-time behavior as described by Levenspie ${ }^{18}$. The kinetics for such reactions is described by (e.g.) Avrami ${ }^{19}$

$$
\delta_{\text {front }}(\mathrm{t})=\delta_{\text {char }}(\mathrm{t}) \cdot\left(1-\exp \left(-\mathrm{M} \cdot \mathrm{t}^{-\mathrm{N}}\right)\right)
$$

the initial condition is

$$
\delta_{\text {front }}(\mathrm{t}=0)=0
$$

where $\mathrm{N}$ is a discrete integer describing the mechanism of nucleii formation. $\mathrm{N}$ is dependent on whether the nucleii are all present from the start or formed at a steady rate. $\mathrm{N}$ also describes whether the nucleii formation 10

\section{AIChE Journal}


happens in 1, 2 or 3 dimensions ${ }^{18}$. The front growth equation (9), presented above, has been used to describe several reaction rate phenomena; e.g. crystallization, adsorption, solid-gas reactions, and catalysis ${ }^{17,20}$. From (9) it is seen that at the time where $\delta_{\text {front }}(t)$ is $63 \%$ of $\delta_{\text {char }}(t)$, the following relation between $M$ and $N$ is valid

$$
M=\left(t_{63 \%}\right)^{-N}
$$

where $t_{63 \%}$ is the time in seconds to achieve $63 \%$ decomposition of the char. The unit of $M$ depends on the value of $N$. In summary, two kinetic parameters, $N$ and $t_{63 \%}$, need to be estimated in order to use the kinetics in the overall intumescent coating model. It is assumed here that nucleii are formed at a steady rate (in three dimensions at the microscopic level) and therefore $\mathrm{N}=4$.

Due to variations in the coating formulation, it is noted that the reactions occurring in the experiments of this work may differ from those presented above. Also other phenomena could influence the decomposition front movement, e.g. mass transfer of gaseous species and a temperature dependency of the decomposition rate. Therefore, the expression in (9) could have several rate phenomena lumped into one equation in a similar manner as (2), which describes the char expansion. This also means that detailed mass balances for eqs. (6)-(8) have not been included in the model; the entire mechanism is represented by eq. (9) and the imposed changes in thermal conductivities.

\section{External heat transfer coefficient}

The heat transfer coefficient, $h$, is determined from experiments as a function of temperature using the uncoated steel-plate experiment and by setting up a heat balance for the steel plate

$$
\mathrm{h} \cdot\left(\mathrm{T}_{\text {gas }}-\mathrm{T}_{\text {sur }}\right)=\left.\rho_{\text {ste }} \cdot \delta_{\text {ste }} \cdot \mathrm{C}_{\mathrm{p}, \text { ste }}(\mathrm{T}) \cdot \frac{\partial \mathrm{T}_{\text {ste }}}{\partial \mathrm{t}}\right|_{t}
$$

where $\mathrm{T}_{\text {sur }}$ is the surface temperature. The steel plate is assumed isothermal and thus $\mathrm{T}_{\text {sur }}=\mathrm{T}_{\text {ste. }}$. In eq 12 , to simplify calculations, heat conduction through the insulation material was neglected. The rate of heat transfer from the gas phase to the bare steel surface was, for typical parameter values, found to be more than 10 times 
higher than the rate of conduction through the insulation material and the assumption considered acceptable in the light of the accuracy of the experimental data.

\section{Solution procedures}

The new engineering model only contains ordinary (as opposed to partial) differential equations. The solution of the model was carried out using the ordinary differential equation solver ODE45 in MatLab. The adjustable parameters were varied manually to match simulations and experimental data of $T_{\text {ins, }}, T_{\text {ste, }}$, the temperatures inside the char, and the char expansion. Due to the uncertainty of the experimental data, no attempt to get very accurate values of the adjustable parameters, using a minimization routine, was carried out. Temperatures inside the char layer were found using interpolation between the surface, decomposition-front and steel temperatures and assuming the heat flux through the char is constant at a given point in time at all positions. This is the same as a thermal resistor network described in Mills ${ }^{21}$. Using the assumption of a thermal resistor network and no significant intra-layer heat evolution from chemical reactions lead to linear temperature profiles in each layer, i.e. carbonaceous char, residue and backside insulation. The temperature in the backside insulation was found by assuming a linear temperature profile between $T_{\text {backside }}$ and $T_{\text {ste. }}$. The data matching was done based on both the 1200 and $2000 \mu \mathrm{m}$. At each time step, the temperature-dependent thermal conductivities of the residual and carbonaceous char, i.e. the two zones separated by the decomposition front, are calculated using the average temperatures in the two zones. The temperature at the decomposition front, at each time step, is calculated using linear interpolation between the temperature at the residual layer surface (facing the gas phase) and that of the isothermal steel. When determining $\frac{\partial \mathrm{T}_{\text {ste }}}{\partial t}$ for the heat transfer coefficient in (12), a $9^{\text {th }}$-order polynomial is fitted to the experimental results. 
A summary of the input parameters for the model is given in Table 2, and the following is a description of the input parameters.

Thermal properties of backside insulation (Superwool ${ }^{\circledR}$ plus)

The thermal conductivity of the backside insulation material is described by

$$
\mathrm{k}_{\mathrm{ins}}(\mathrm{T})=0.0348 \cdot \mathrm{e}^{0.00201 \cdot \mathrm{T}}
$$

The correlation was derived from data in the supplier product sheet, where the thermal conductivity is provided for every $200{ }^{\circ} \mathrm{C}^{22}$. T must be inserted in ${ }^{\circ} \mathrm{C}$.

Properties of the steel

An expression for the heat capacity of C16 steel is derived from data in Incropera and De Witt ${ }^{23}$

$$
\mathrm{C}_{\mathrm{p}, \mathrm{ste}}(\mathrm{T})=2.364 \cdot 10^{-6} \cdot \mathrm{T}^{3}-1.758 \cdot 10^{-3} \cdot \mathrm{T}^{2}+0.783 \cdot \mathrm{T}+420.209
$$

where $\mathrm{T}$ must be inserted in ${ }^{\circ} \mathrm{C}$ and $\mathrm{C}_{\mathrm{p} \text {,ste }}$ is given in the unit $\mathrm{J} \cdot \mathrm{kg}^{-1} \cdot \mathrm{K}^{-1}$.

The density of steel is set to constant values defined at room temperature ${ }^{23}$.

\section{Effective thermal conductivity of char layers}

For the effective thermal conductivity of the carbonaceous char, $\mathrm{k}_{\mathrm{carb}, \mathrm{char}}$, and the residue, $\mathrm{k}_{\text {residue, }}$ an expression specifically developed for intumescent chars by Di Blasi and Branca ${ }^{24}$ is used. The expression includes contributions from both radiation in the pores and conduction in the gas and solid phase

$$
\mathrm{k}(\mathrm{T})=\frac{\mathrm{k}_{\text {skeletal }}(\mathrm{T}) \cdot \mathrm{k}_{\text {gas }}(\mathrm{T})}{(1-\varepsilon) \cdot \mathrm{k}_{\text {gas }}(\mathrm{T})+\mathrm{k}_{\text {skeletal }}(\mathrm{T}) \cdot \varepsilon}+13.5 \cdot \sigma \cdot(\mathrm{T})^{3} \cdot \frac{\mathrm{d}_{\mathrm{b}}}{\varepsilon \cdot \epsilon}
$$

where $\sigma$ is the Stefan-Boltzmann constant, $\mathrm{d}_{\mathrm{b}}$ is the pore diameter, and $\epsilon$ is the emissivity of the coating.

$\mathrm{k}_{\text {skeletal }}$ and $\mathrm{k}_{\text {gas }}$ are the thermal conductivity of the solid char and gas, respectively. $\varepsilon$ is the porosity of the char. The pore diameter, $d_{b}$, is assumed independent of temperature. The temperature must be inserted in eq. 
(15) in K. The temperature dependencies are based on the arithmetic mean of either the carbonaceous char layer or the residue layer.

Thermal conductivity of gas phase

The thermal conductivity of the gas inside the char, $\mathrm{k}_{\mathrm{gas}}$, is described by the expression provided by Di Blasi and

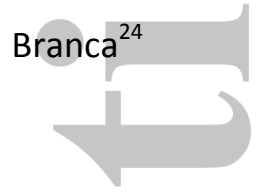

$$
\mathrm{k}_{\text {gas }}(\mathrm{T})=4.815 \cdot 10^{-4} \cdot \mathrm{T}^{0.717}
$$

where $\mathrm{T}$ is in $\mathrm{K}$ and $\mathrm{k}_{\text {gas }}$ is in $\mathrm{W} \cdot \mathrm{K}^{-1} \cdot \mathrm{m}^{-1}$.

\section{Porosity of char layer}

The porosity, $\varepsilon$, of the char is crudely estimated by a simple relation of proportionality

$$
\varepsilon=1-\frac{\delta_{0} \cdot\left(1-\varepsilon_{0}\right)}{\delta_{\text {char,final }}}
$$

where $\varepsilon_{0}$ is the initial porosity of the coating. It is noted that equation (17), due to lack of a reliable number, neglects the effect of solids being converted to gas during the intumescence process.

Thermal conductivity of solid

To estimate the skeletal thermal conductivity, $\mathrm{k}_{\text {skeletal, }}$ of the solid in the porous char, an expression derived by Palankovski ${ }^{25}$ for the temperature dependence of the thermal conductivity of solids is used

$$
\mathrm{k}_{\text {skeletal }}(\mathrm{T})=\mathrm{k}_{300} \cdot\left(\frac{\mathrm{T}}{300}\right)^{\beta}
$$

where $\mathrm{k}_{300}$ is the thermal conductivity at $300 \mathrm{~K}$, and $\beta$ is an empirical parameter. The values are assumed to be the same in the carbonaceous char and the residue. $\beta$ was assumed to be unity and $k_{300}$ taken to $1.38 \mathrm{~W} /(\mathrm{K} \cdot \mathrm{m})$ (corresponding to that of $\left.\mathrm{SiO}_{2}\right)^{25}$. The values used are not important for the simulations because the thermal conductivity of the char is dominated by the gas phase conductivity (solids volume fraction is only a few percent). 


\section{Adjustable parameters}

In addition to the input parameters described in the previous paragraph, the simulations are based on some adjustable parameters. A summary of these and their values after matching of experiments and simulations is given in Table 3. The parameters are described in the following and a separate section with discussion and validation of the adjustable parameter values from the data matching is provided in a later paragraph.

\section{Rate constant for char expansion}

The rate constant, $\mathrm{k}_{\mathrm{r}}$, describing the char expansion is given by an Arrhenius expression

$$
\mathrm{k}_{\mathrm{r}}(\mathrm{T})=\mathrm{k}_{0} \cdot \exp \left(\frac{-\mathrm{E}_{\mathrm{a}}}{\mathrm{R} \cdot \mathrm{T}}\right)
$$

where $k_{0}$ is the pre-exponential factor, $E_{a}$ is the activation energy and $R$ is the gas constant. Both $k_{0}$ and $E_{a}$ are adjustable parameters in the model.

Pore diameter and emissivity

The pore diameter divided by emissivity describes the effect of intra-char radiation in the effective thermal conductivity shown in (15). The ratio between these, $d_{\epsilon}$, is defined as

$$
\mathrm{d}_{\epsilon}=\frac{\mathrm{d}_{\mathrm{b}}}{\epsilon}
$$

where $d_{\epsilon}$ in the carbonaceous char and the residue layer are referred to as $d_{\epsilon, \text { carb,char }}$ and $d_{\epsilon, \text { residue, }}$ respectively. Both these parameters are adjustable in the model.

\section{Parameter affecting the decomposition front}

The parameter describing the movement of the decomposition front, $\mathrm{t}_{63 \%}$, is an adjustable parameter in the model. A change in $t_{63 \%}$ will displace the onset of the decomposition front movement.

\section{Results and discussion}


In this section, the experimental results obtained are first explained and discussed with respect to repeatability. Then follow simulations and model validation. Finally, a sensitivity analysis and parameter study of the model and evaluation of assumptions are discussed.

Experimental series and repeatability

Several experimental series were conducted in the pilot-scale furnace with repetitions included to evaluate the uncertainty. To provide a visual impression of the char formed, a photo taken after 3 hours of heating and subsequent cooling to room temperature is seen in Figure 4. The intumescent coating has expanded from about $1 \mathrm{~mm}$ to about $4.5 \mathrm{~cm}$. The expansion was fairly uniform in the large middle zone of the coated substrate, whereas somewhat lower expansion was observed near the edges of the char. The inside of the char was completely white, the color originating from $\mathrm{TiO}_{2}$ and titanium pyrophosphate formed during the intumescence ${ }^{5}$. A thin (about $1 \mathrm{~mm}$ ) layer of a yellow material had formed on the outer surface of the char. The chemical nature of this top layer was not identified, but it appeared in all the experiments and probably originates from an incipient chemical conversion of the presumably inorganic, white char at high temperatures. Another important observation in Figure 5 is the rough morphology of the outer surface, which is most likely formed when gas bubbles, released by the blowing agent, reach the char surface but not overcoming the surface tension of the molten char phase.

To aid the subsequent model discussion, temperature-time curves measured in the furnace are shown in Figure 5 with indication of four characteristic time periods, termed P1-P4 (shown as an example for the thermocouple initially placed $1 \mathrm{~cm}$ above the coated steel substrate). The four curves represent the following:

- $\quad \mathrm{P} 1$ is the time period prior to a thermocouple being covered by the expanding char.

- $\quad$ P2 is the time period during which a falling temperature is observed.

- $\quad \mathrm{P} 3$ is the time period with a close to constant temperature increase.

- $\quad$ P4 is the time period during which the temperature increases at a lower rate. 
During P4, the steel reaches the critical temperature of about $500{ }^{\circ} \mathrm{C}$. The backside insulation temperature (measured at a position $6 \mathrm{~cm}$ behind the steel substrate) is also shown.

In Figures 6 and 7, repetitions of the two furnace experiments employing an initial coating thickness of 1200 $\mu \mathrm{m}$ and $2000 \mu \mathrm{m}$, respectively, are compared. An excellent agreement is evident for all temperatures, except at positions farthest away from the steel substrate $(3$ and $4 \mathrm{~cm})$, where the arrival, to the immobilized thermocouples, of the expanding char (and subsequent development of an irregular surface) is bound to be more uncertain. For the experiments with a $2000 \mu \mathrm{m}$ coating, the repeatability at $3 \mathrm{~cm}$, is, however, also quite good. The backside insulation temperature shows quite some variation between the experiments. This can be attributed to practical challenges of keeping the thermocouple immobilized at the right position when closing the furnace opening prior to initiation of an experiment. Consequently, this temperature reading is less reliable than the other measurements.

In Figures 8 and 9, all indirect char expansion measurements, conducted using the thermocouples in the furnace, are shown. A reasonably good repeatability can be seen, especially at short times of experimentation. The rate and extent of expansion are fairly similar for the two initial coating thicknesses. Shi and Chew $^{4}$ pointed out the repeatability of expansion measurements as being particular challenging. Note, that the entire expansion takes place in the first 20-30 minutes of the experiments. The final thickness measured after 3 hours and cooling to room temperature was about $4.5 \mathrm{~cm}$ at the center where the thermocouples are placed. A single experiment showed an expansion of about $5.5 \mathrm{~cm}$. The measurements, due to the irregular char top surfaces, are subject to uncertainty, but keeping the model assumptions in mind, this uncertainty seems acceptable for the model validation. As char, and subsequently the residual layer, are formed, gaps may form in the structure, through which increased radiative heat transfer can take place. However, a rapid temperature increase in one or more of the various layers, which could be ascribed to such a phenomenon, was not observed in the intra-char experimental data. 


\section{Model simulations}

As mentioned in an earlier paragraph, it is of practical importance to develop engineering models of a low degree of complexity. Simulations with the model derived earlier are now presented in the following.

The heat transfer coefficient was calculated over two hours of experimentation. In the first minute the value drops from $500 \mathrm{~W} \cdot \mathrm{m}^{-2} \cdot \mathrm{K}^{-1}$ and afterwards it becomes stable with an average value of $34 \mathrm{~W} \cdot \mathrm{m}^{-2} \cdot \mathrm{K}^{-1}$. This value is used in the following simulations. The high value in the beginning of the experiment is due to the rapid increase of the gas temperature.

In Figures 8 and 10, simulations are compared to the experimental data series for an initial coating thickness of $1200 \mu \mathrm{m}$. Adjustable parameters used in the simulations for the char expansion $\left(k_{0}\right.$ and $\left.E_{a}\right)$, for the temperature-time development $\left(\mathrm{d}_{\epsilon, \text { carb,char }}, \mathrm{d}_{\epsilon, \text { residue }}\right)$, and the decomposition front movement $\left(\mathrm{t}_{63 \%}\right)$ are provided in Table 3. There is a very good agreement between simulations and experimental char expansion data. For the temperature curves, a good qualitative agreement, capturing most of the behavior, is evident, in particular for the steel substrate and at the positions 1 and $2 \mathrm{~cm}$. However, in the upper parts of the char layer, at positions 3 and $4 \mathrm{~cm}$, the time to coverage of the thermocouples are very uncertain and this is reflected in the poor agreement. Additionally, the temperature difference between simulated and experimental results after coverage of the thermocouples is due to the uncertainty in expansion measurements and simulated steel temperature. There is also some deviation for the temperature inside the back side insulation material, but, due to the large uncertainty of this particular measurement, this is of less importance.

In Figures 11 and 9, simulations and experimental data for an experiment with initial coating thickness of 2000 $\mu \mathrm{m}$ are shown. The adjustable parameters are provided in Table 3. Similarly to the experiments with a $1200 \mu \mathrm{m}$ coating, the best fits are obtained close to the steel plate where the experimental repeatability was also the best. The moving decomposition front starts about 20 minutes later than in the $1200 \mu \mathrm{m}$ experiments. The kinetic parameters for the expansion (i.e. the activation energy, $E$, and the pre-exponential factor, $k_{0}$ ) applied in the model were the same for both coating thicknesses (1200 and $2000 \mu \mathrm{m})$. The decomposition 
parameter, $\mathrm{t} 63 \%$, which basically determines the initiation of the decomposition front, is almost the same for the two coating thicknesses (5580 and $6300 \mathrm{~s}$, respectively). The small difference can be ascribed to the higher char density for the $2000 \mu \mathrm{m}$ case (the char expansion is the same for the two coating thicknesses, so the char density must be higher, though still very low, for the thicker coating). Finally, the two parameters left to describe the difference between the temperature curves at long reaction times (>about $100 \mathrm{~min}$ ) for the two thicknesses are the char pore diameters divided by the solid emissivity on each side of the decomposition front, $d_{\varepsilon, \text { carb,char }}$ and $d_{\varepsilon, \text { residue, }}$ which are 250 and $190 \mu \mathrm{m}$, and 300 and 225 $\mu \mathrm{m}$, respectively, for the 1200 and $2000 \mu \mathrm{m}$ coating. This difference can again be ascribed to the higher char density for the $2000 \mu \mathrm{m}$ coating, which can result in a different char pore size. In summary, the char expansion development and the intra-char temperature curves observed for the two coating thicknesses can be described with the same model parameters except for some differences in pore size diameters and initiation of decomposition front movement.

As shown in figures 8 and 9, the experimental data shows a maximum char expansion of $4.0 \mathrm{~cm}$ for both coating thicknesses $(1200$ and $2000 \mu \mathrm{m})$. The expansion factor is very high $(>20)$ and apparently there is no strong effect of film thickness on the maximum expansion (at least not for the two cases considered). The char must be more dense in the $2000 \mu \mathrm{m}$ case (though still very low), but as shown in figures 10 and 11 this does not, to any great extent, influence the temperature profiles measured.

In summary, it is possible to get a reasonably good description of the coating behavior using a single overall reaction for the char expansion coupled with a simple expression for a decomposition front and an energy balance of the steel substrate.

The simulated thickness of the decomposed zone can be observed from Figures 10 and 11 . As an example it is seen from Figure 10 that after 55 minutes the decomposition front has moved $0.5 \mathrm{~cm}$ away from the surface and after 105 minutes it has moved $3.5 \mathrm{~cm}$ away from the surface. 
It is noted that the model excludes the heat of reaction(s), and the slope change due to the decomposition front movement only shows up in the simulations because of different thermal conductivity properties in the carbonaceous char and the residue (on each side of the front). The properties used in the simulations are close to those of air due to the high porosity of the char. During the model development, heat of carbon oxidation was also included. However in this given case this did not lead to significant changes in the temperatures inside the char, and the simulations are not described in detail in this work. However, the finding is rather surprising and a few remarks on the topic are given in the following. In an earlier study ${ }^{5}$ the oxygen content in the furnace was calculated to be 1 vol\% from a stoichiometric mole balance. Additionally, it was observed visually (crosssection view) from the experiments in the present work that the decomposition front had moved through the entire char after the 3 hours. By implementing an oxygen diffusion-controlled oxidation front ${ }^{18}$, it was found that the carbon fraction in the carbonaceous char could at a maximum be $3 \mathrm{wt} . \%$. This is the maximum mass fraction that would allow the front to move through the char in 3 hours. The heat generated from combustion of this carbon content accounts for $6 \%$ of the total energy transferred to the system. In the simulations, the effect of this energy addition over the 3 hours of experiments becomes insignificant because the increased temperature leads to reduced heat transfer from the gas into the expanded coating. Therefore it can be concluded that the heat of reaction does not have a significant influence on the steel temperature in the experiments.

As a final note, the model use as input the post-heated char expansion, which was one of the main critiques of current models pointed out by Griffin ${ }^{6}$. However, several data points, sampled during the experiments at different values of time, were used to validate the char expansion rate, thereby not relying on the post heated expansion only.

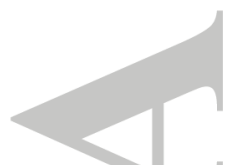

\section{Sensitivity analysis of model simulations}


A sensitivity analysis of the model with respect to the adjustable parameters was performed under the conditions of Figure 10 with a $1200 \mu \mathrm{m}$ experiment (termed base case). The parameters $E_{a}, k_{0}, d_{\epsilon, \text { carb,char, }}$ $d_{\epsilon, \text { residue, }}$ and $t_{63 \%}$ were reduced to $80 \%$ of the values given in Table 3 . The simulation results of the steel temperature and the temperature $1 \mathrm{~cm}$ above the steel plate are seen in Figure 12 . The parameter $\mathrm{t}_{63 \%}$ affects the time of the onset of the characteristic slope change and the main effect is seen in the simulations of the temperature $1 \mathrm{~cm}$ above the steel plate. From the simulations the effect of the parameters describing the thermal conductivity is small. This is because these parameters describe the heat transfer due to radiation. At low temperatures the main contribution to the thermal conductivity is from the gas inside the char. In addition, this shows that the slope change between P3 and P4 is mainly due to the different temperatures on each side of the moving front which causes different values of $k_{\text {residue }}$ and $k_{\text {carb,char }}$.

The parameters affecting expansion are seen to have a large influence on the temperatures.

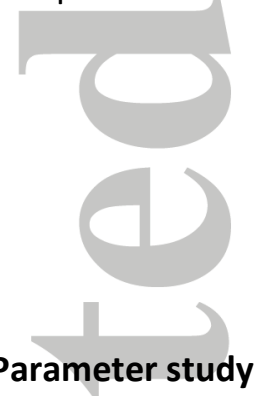

The validated model was also used to study the influence of selected process parameters, namely the thickness of the steel and the gas temperature. These parameters were increased by $10 \%$, and Figure 13 shows the effect on the steel temperature and the temperature $1 \mathrm{~cm}$ inside the char. The changes in these two parameters show increasing effect over time, and for a time period of approximately 15 minutes, the effect is almost non-existent. This is because the expansion is affected by the temperatures and a reduced gas temperature leads to a slower expansion which then increases the heat transfer to the steel. The same effects are observed $1 \mathrm{~cm}$ inside the char. 


\section{Evaluation of adjustable parameters}

An advantage of the model presented in this work is that it requires only two adjustable input parameters

related to the char expansion $\left(E_{a}\right.$ and $\left.k_{0}\right)$, two for char insulation properties $\left(d_{\epsilon, \text { carb,char, }}, d_{\epsilon, \text { residue }}\right)$, and one related to the decomposition front $\left(\mathrm{t}_{63 \%}\right)$. In the following, a discussion of the adjustable parameters used in the model is provided and values are compared with data from literature sources. A summary of the adjustable model parameters is provided in Table 3.

\section{Arrhenius parameters for expansion reaction}

The fitted value of the pre-exponential factor, $\mathrm{k}_{0}$, is $15 \mathrm{~s}^{-1}$, and is considered realistic. Pre-exponential factors for expansion reactions can vary significantly, for instance in the study by Caglostro et al. ${ }^{26}$, values in the range from five to $6.9 \cdot 10^{5} \mathrm{~s}^{-1}$ were found, and Griffin ${ }^{6}$ reported values of 71 to $1.7 \cdot 10^{5} \mathrm{~s}^{-1}$ for the melting and intumescence reactions, which were used to describe the expansion process.

The activation energies used in the studies by Caglostro et al. ${ }^{26}$ are between 53 and $93 \mathrm{~kJ} \cdot \mathrm{mol}^{-1}$. Similarly, Griffin found values for the melting and intumescence reaction to be in the range of 39 to $95 \mathrm{~kJ} \cdot \mathrm{mol}^{-1}$, which is close to the $34 \mathrm{~kJ} \cdot \mathrm{mol}^{-1}$ used in this study.

\section{Char insulation properties}

In this work a temperature dependency of the thermal conductivity of char developed by Di Blasi and Branca ${ }^{24}$ especially for intumescent coatings has been used. It consists of a part describing the conduction and a part describing the radiative heat transfer. However, the value of the radiation part is relatively small, and at temperatures below $500{ }^{\circ} \mathrm{C}$, the thermal conductivity of the char is almost identical to that of air. This can be seen from Figure 14, where values from literature are compared to the values used in this work. The difference between the reported values may originate from both the method of investigation and the coating formulations used.

Decomposition front 
Although the exact value of $t_{63 \%}$ describing the decomposition front is difficult to validate, a short discussion of the mechanism is given in the following. The parameters are fitted according to Avrami ${ }^{19}$ kinetics, which are similar to Prout-Tompkins models ${ }^{18,27}$. This model has been used for the study of biomass degradation ${ }^{28}$. The mechanism also explains why the front starts moving at a late stage in the experiments because the phosphorous ester has to decompose before oxidation occurs. Additionally, some earlier research supports that oxygen diffusion is not the limiting mechanism of the oxidation. This can be seen from the following deduction. In our earlier research on primers for intumescent coatings, it was shown experimentally that the primer is exposed to oxygen after 22 minutes in the furnace. This corresponds to a steel temperature of $300{ }^{\circ} \mathrm{C}^{5}$ and is significantly earlier than the decomposition front reaches the steel plate in the experiments used for model validation. Additionally, Griffin et al. ${ }^{7}$ determined that the thermo gravimetric behavior of intumescent coatings is independent of oxygen content in the gas at temperatures up to $540{ }^{\circ} \mathrm{C}$. This is similar to the $600{ }^{\circ} \mathrm{C}$ where reaction (6) (decomposition of the phosphorous ester) is reported to initiate. Examination of Figures 6 and 7 shows that the change between P3 and P4 does not take place at temperatures below $550{ }^{\circ} \mathrm{C}$. Based on the temperatures described in this paragraph it is therefore concluded that oxygen is present at the steel plate and at a lower temperature than the one at which the decomposition front initiates. Therefore diffusion of oxygen is not the rate-limiting mechanism, and the front does not move before decomposition of the phosphorous ester has occurred. In summary, oxygen is available for the oxidation/decomposition throughout the entire expanded coating and therefore the limiting mechanism must be found in the solid state.

\section{Validation of model assumptions}

A number of assumptions are underlying the model development. The most important of these are discussed

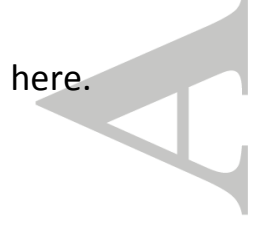


Shrinkage of the char was assumed to be negligible. Although this assumption cannot be completely verified none of the covered thermocouples were later uncovered. Therefore, any degree of shrinkage would be very low.

It was assumed that the char expansion can be described by a single first-order reaction. This is obviously not correct as the expansion is the combination of at least three chemical reactions ${ }^{5}$, but the assumption was included to keep the number of adjustable parameters low. Results presented show that the expansion can be properly described this way, but the effects of formulation variables are only expressed indirectly.

Convection inside the pores in the char is neglected. This is supported by Kantorovich and Bar-Ziv's review on heat transfer in porous chars, in which it is mentioned that for pores less than $1 \mathrm{~cm}$ in porous chars, heat transfer due to convection can usually be neglected ${ }^{29}$.

The char was considered intact at all times and effects of surface cracks neglected. This was verified by inspecting the chars after heating. Also, damages in the char, for instance due to primer failure, can easily be observed from the temperature profiles, as shown in our earlier work ${ }^{5}$.

Another assumption is that the radiation from the furnace walls is neglected. Although this cannot be completely verified, work by Staggs ${ }^{30}$ on steel beams coated with high and low (non-intumescent) emissivity coatings in a furnace show that the heat transfer contribution of radiation is small. However, if the fire curve is steeper than for the cellulosic type fire scenario (e.g. for hydrocarbon fires), the effect of radiation is expected to be more pronounced.

\section{Conclusions}

A mathematical model, describing the behavior of an intumescent coating on a steel substrate exposed to heating in a cellulosic type fire, was developed. The most relevant phenomena, char formation, expansion and oxidation, and subsequent transient developments in char, steel substrate, and backside insulation temperatures were included. Experimental data series obtained in a pilot-scale, gas-fired furnace, at realistic 
gas temperatures and time scales, were used for model validation. A good qualitative agreement between simulations and experiments was found. The char expansion was modelled using an overall chemical reaction and for the two coating thicknesses investigated, the same values were used for the rate constant and activation energy. An important outcome of the investigation is a documentation of the necessity to measure temperatures inside the expanding char layer when validating mathematical models. If only the steel substrate temperature and the char expansion are measured, it is rather easy to get a good quantitative match of simulations and experimental data. Supplementing with intra-char temperatures provide a much more challenging set of data, useful for mapping of important mechanisms. A limitation of the present model is that specific details on the coating formulation are not directly expressed, only macroscopic properties, such as pore size and degree and rate of expansion, reflect the formulation.

The model developed is sufficiently simple (ordinary differential equations) and relies on a low number of input and kinetic parameters, giving it potential as an engineering tool that can be used for practical pilot-scale evaluation of intumescent coatings. Future work should involve an extension to other coating formulations for cellulosic fires, as well as an adaptation to coatings for hydrocarbon fires with very high heating rates (room temperature to $1100 \mathrm{C}$ in about $5 \mathrm{~min}$ ), substantially higher than for cellulosic fires (room temperature to 1100 C in about three hours). Furthermore, the proposed decomposition-oxidation mechanism needs to be chemically confirmed.

\section{Acknowledgements}

Financial support by The Hempel Foundation is gratefully acknowledged.

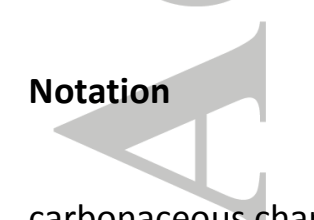

carbonaceous char

char non oxidized part of char

all expanded coating 


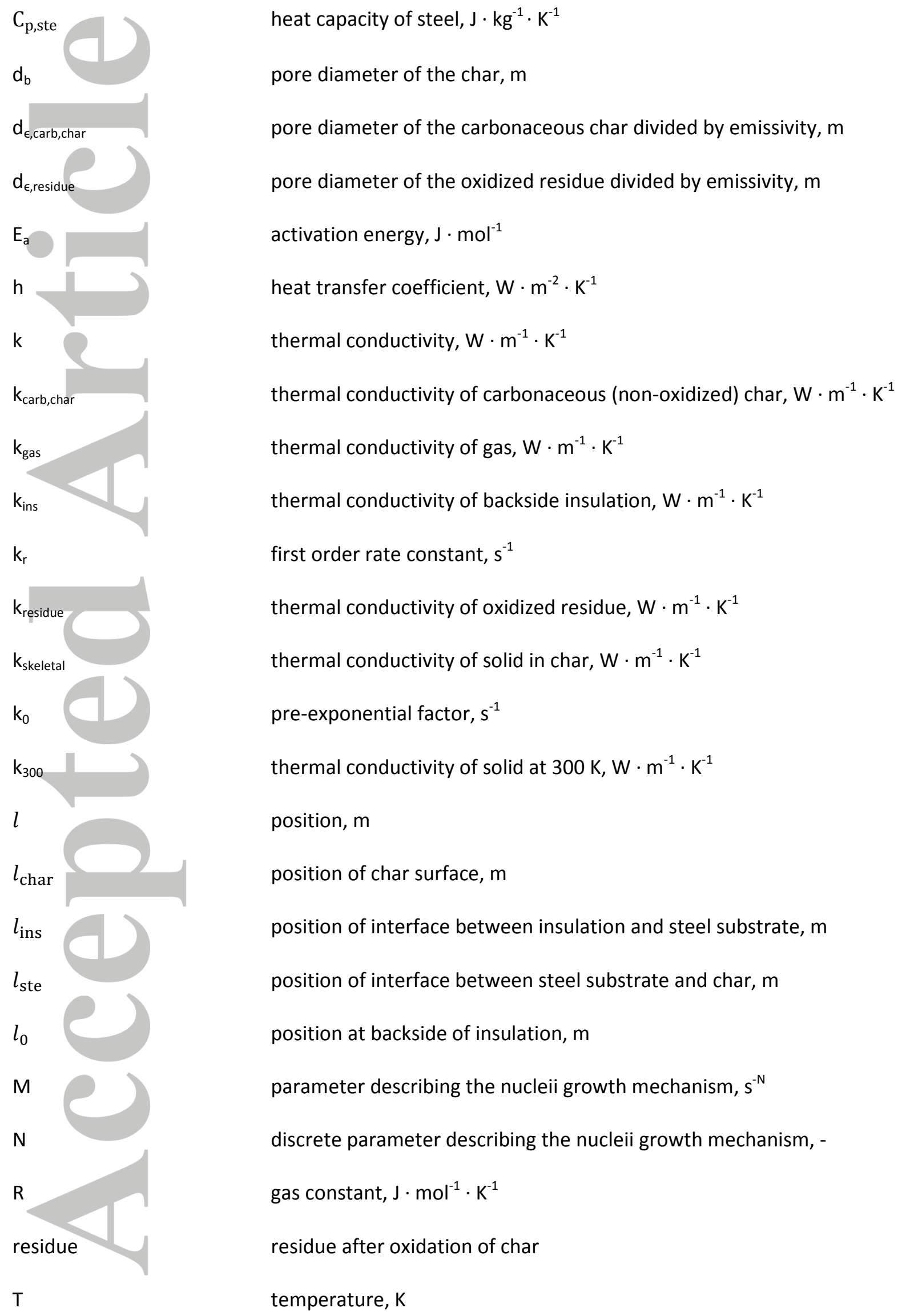


$t$
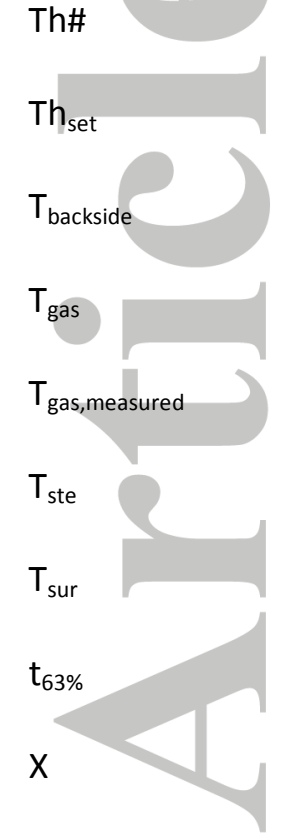

\section{Greek letters}

$\beta$
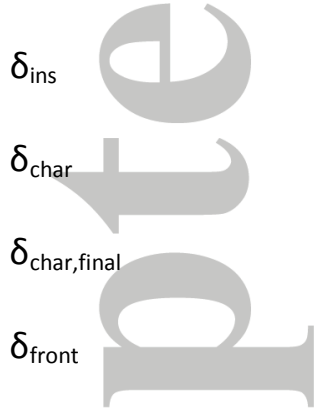

$\delta_{\text {ste }}$

$\delta_{0}$

$\varepsilon$

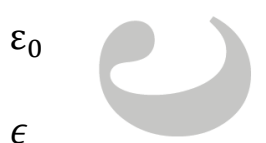

$\epsilon$

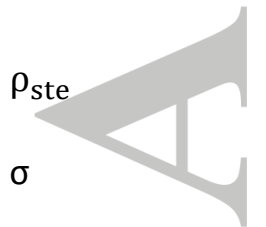

time, $s$

thermocouple, \# refers to distance to steel substrate in $\mathrm{cm}$

thermocouple measuring the gas temperature

temperature at backside of insulation, $\mathrm{K}$

gas temperature, $\mathrm{K}$

measured gas temperature, $\mathrm{K}$

temperature of isothermal steel substrate, $\mathrm{K}$

surface temperature, $\mathrm{K}$

time for decomposition front to reach $63 \%$ conversion, $\mathrm{s}$

solids conversion, -

empirical constant in temperature dependency of thermal conductivity, -

thickness of backside insulation, $\mathrm{m}$

thickness of char, $\mathrm{m}$

final thickness of char, $m$

thickness of decomposed zone, $\mathrm{m}$

thickness of steel substrate, $\mathrm{m}$

initial intumescent coating thickness, $\mathrm{m}$

porosity, -

initial coating porosity, -

emissivity, -

density of steel, $\mathrm{kg} \cdot \mathrm{m}^{-3}$

Stefan-Boltzmann constant, $5.6703 \cdot 10^{-8} \mathrm{~W} \cdot \mathrm{m}^{-2} \cdot \mathrm{K}^{-4}$

AlChE Journal

This article is protected by copyright. All rights reserved. 


\section{Literature Cited}

1. Bourbigot S, Le Bras M, Duquesne S, et al. Recent advances for intumescent polymers. Macromolecular Materials and Engineering 2004; 289: 499-511.

2. Weil ED. Fire-Protective and Flame-Retardant Coatings-A State-of-the-Art Review. J Fire Sci 2011; 29: 259296.

3. Bourbigot $S$ and Duquesne $S$. Fire retardant polymers: recent developments and opportunities. J.Mater.Chem. 2007; 17: 2283-2300.

4. Shi L and Chew MYL. A review of fire processes modeling of combustible materials under external heat flux. Fuel 2013; 106: 30-50.

5. Nørgaard KP, Dam-Johansen K, Català $P$, et al. Laboratory and gas-fired furnace performance tests of epoxy primers for intumescent coatings. Prog Org coat 2014; 77: 1577-1584.

6. Griffin G. The Modeling of Heat Transfer across Intumescent Polymer Coatings. J Fire Sci 2010; 28: 249-277.

7. Griffin GJ, Bicknell AD and Brown TJ. Studies on the effect of atmospheric oxygen content on the thermal resistance of intumescent, fire-retardant coatings. J Fire Sci 2005; 23: 303-328.

8. Jimenez $\mathrm{M}$, Duquesne $\mathrm{S}$ and Bourbigot $\mathrm{S}$. Multiscale experimental approach for developing high-performance intumescent coatings. Ind Eng Chem Res 2006; 45: 4500-4508.

9. Jimenez M, Duquesne S and Bourbigot S. High-throughput fire testing for intumescent coatings. Ind Eng Chem Res 2006; 45: 7475-7481.

10. van Hees P, Andersson P, Hjohlman M, et al. Use of the Cone Calorimeter and ConeTools software for development of innovative intumescing graphite systems. Fire Mater 2010; 34: 367-384.

11. Zhang F, Zhang J and Wang Y. Modeling study on the combustion of intumescent fire-retardant polypropylene. Express Polymer Letters 2007; 1: 157-165.

12. Butler KM. Physical modeling of intumescent fire retardant polymers ACS Symposium Series, 1997, p.214.

13. Mamleev VS, Bekturov EA and Gibov KM. Dynamics of intumescence of fire-retardant polymeric materials. J Appl Polym Sci 1998; 70: 1523-1542.

14. Bourbigot S, Duquesne S and Leroy JM. Modeling of heat transfer of a polypropylene-based intumescent system during combustion. J Fire Sci 1999; 17: 42.

15. Nicholas J, White DR and Wiley J. Traceable temperatures: an introduction to temperature measurement and calibration. Wiley, 2001.

16. Horacek H. Reactions of stoichiometric intumescent paints. J Appl Polym Sci 2009; 113: 1745-1756.

17. Khawam A and Flanagan DR. Solid-state kinetic models: Basics and mathematical fundamentals. J Phys Chem B 2006; 110: 17315-17328. 
18. Levenspiel O. The Chemical reactor omnibook. OSU, 1993.

19. Avrami M. Kinetics of phase change. II. Transformation-time relations for random distribution of nuclei. J Chem Phys 1940; 8: 212-224.

20. Brown ME. The Prout-Tompkins rate equation in solid-state kinetics. THERMOCHIMICA ACTA 1997; 300: $93-$ 106.

21. Mills AF. Heat Transfer / International Student Edition. IRWIN, 1992.

22. http://ereader.morgantechnicalceramics.com/emags/european_product_databook_080911/print/print.pdf 18.02.2014.

23. Incropera FP and DeWitt DP. Introduction to heat transfer. Wiley, 1990.

24. Di Blasi C and Branca C. Mathematical model for the nonsteady decomposition of intumescent coatings. AICHE J 2001; 47: 2359-2370.

25. Palankovski V. Simulation of Heterojuncion Bipolar TransistorsDissertation Technical University of Wien, 2000.

26. Cagliostro D, Riccitiello S, Clark K, et al. Intumescent coating modeling. J Fire \& Flammability 1975; 6: 205222.

27. Prout EG and Tompkins FC. The thermal decomposition of potassium permanganate. Transactions of the Faraday Society 1944; 40: 488-498.

28. Garcia Barneto A, Ariza Carmona J, Martin Alfonso JE, et al. Simulation of the thermogravimetry analysis of three non-wood pulps. Bioresour Technol 2010; 101: 3220-3229.

29. Kantorovich II and Bar-Ziv E. Heat transfer within highly porous chars: a review. Fuel 1999; 78: 279-299.

30. Staggs JEJ and Phylaktou HN. The effects of emissivity on the performance of steel in furnace tests. Fire Saf J 2008; 43: 1-10.

31. Stoliarov SI, Crowley S, Walters RN, et al. Prediction of the burning rates of charring polymers. Combust Flame 2010; 157: 2024-2034.

32. Lautenberger C and Fernandez-Pello C. Generalized pyrolysis model for combustible solids. Fire Saf J 2009; 44: 819-839.

33. Farkas E, Meszena Z, Toldy A, et al. Modelling of transport processes in a developing char. Polym Degrad Stab 2008; 93: 1205-1213.

34. Bai Y, Vallée T and Keller T. Modeling of thermal responses for FRP composites under elevated and high temperatures. Composites Sci Technol 2008; 68: 47-56. 
35. Bai Y and Keller T. Time dependence of material properties of FRP composites in fire. J Composite Mater 2009; 43: 2469.

36. Feih S, Mathys Z, Gibson A, et al. Modelling the compression strength of polymer laminates in fire. Composites Part A: Applied Science and Manufacturing 2007; 38: 2354-2365.

37. Trelles J and Lattimer BY. Modelling thermal degradation of composite materials. Fire Mater 2007; 31: 147171.

38. Bahramian AR, Kokabi M, Famili MHN, et al. Ablation and thermal degradation behaviour of a composite based on resol type phenolic resin: Process modeling and experimental. Polymer 2006; 47: 3661-3673.

39. Wang L, Wang Y, Yuan J, et al. Thermal conductivity of intumescent coating char after accelerated aging. Fire Mater 2013; 37: 440-456.

40. Staggs JEJ. Thermal conductivity estimates of intumescent chars by direct numerical simulation. Fire Saf J 2010; 45: 228-237.

41. Gomez-Mares M, Tugnoli A, Landucci G, et al. Behavior of intumescent epoxy resins in fireproofing applications. J Anal Appl Pyrolysis 2012; 97: 99-108.

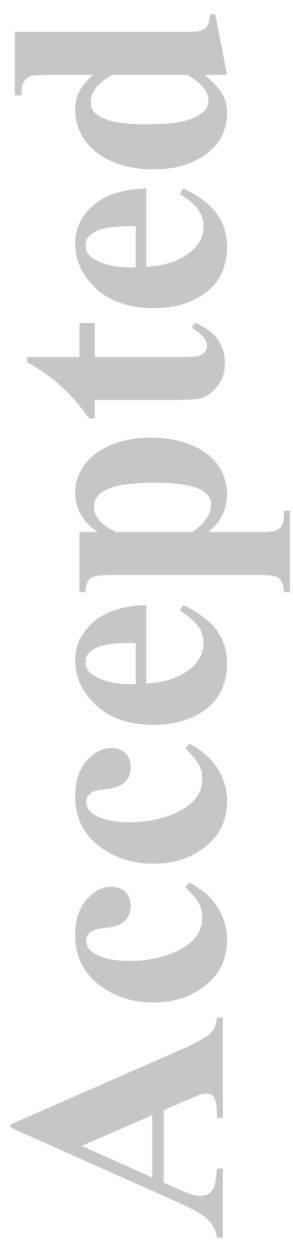


Table 1. Recent mathematical models of intumescent coatings with year of publication and equipment and time span used when validating the models. Other details can be found in Shi and Chew ${ }^{4}$.

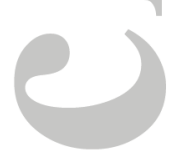

Table 2. List of input parameters to simulations. Reference to an equation number is provided where the parameter is calculated using an equation or correlation.

Table 3. Values of adjustable parameters used in the mathematical model. Values for both the 1200 and 2000 $\mu \mathrm{m}$ simulations are shown.

Figure 1. Photo of furnace with dimensions in mm. The coated steel substrate (cannot be seen) is inserted in a vertical position opposite to the viewing port. Arrows indicate inner dimensions.

Figure 2. A principal drawing of the experimental system inside the furnace (seen from above). On the drawing, the temperatures measured are indicated. Dimensions are all provided in $\mathrm{mm}$. "Th" refers to thermocouples, where the subscripts "ins", is the insulation, "ste" is the steel, "set" is the set point thermocouples and "Th1-5" are thermocouples at positions from 1 to $5 \mathrm{~cm}$ above the steel substrate. Furnace stone material is placed around the steel substrate.

Figure 3. Schematic illustration of the model system, showing the main mechanisms included in the model. Not to scale. Positional variables are shown below the figure and temperatures above. $\delta_{\text {ins }}, \delta_{\text {ste, }}$ and $\delta_{\text {char }}$ represent the thickness of the backside insulation, the steel substrate and the char, respectively. $\delta_{\text {front }}$ represents the thickness of the decomposed zone. The vertical dotted line shows the interface between carbon containing char and inorganic residue.

Figure 4. Photo of expanded char after 3 hours of heating in the furnace. The five uncovered metal thermocouples, placed above the char, can be seen close to the center of the char surface. The thermocouples already covered cannot be seen.

Figure 5. Measured temperatures for an experiment with a $1200 \mu \mathrm{m}$ thick intumescent coating. For the thermocouple placed $1 \mathrm{~cm}$ above the steel substrate, the temperature-time curve is divided into four time periods, termed P1-4. Temperatures of the gas, the backside insulation, the steel substrate and various positions above the steel substrate are also shown. 
Figure 6. Example of the repeatability of experiments conducted in the furnace. The figure shows a comparison of temperatures for the two experiments (referred to as expland 2) employing a coating thickness of $1200 \mu \mathrm{m}$.

Figure 7. Example of the repeatability of experiments conducted in the furnace. The figure shows a comparison of temperatures for the two experiments (referred to as exp3 and 4) employing a coating thickness of $2000 \mu \mathrm{m}$.

Figure 8. Experimental and simulated expansion-time behavior for a coating of thickness $1200 \mu \mathrm{m}$. Expl and 2 refers to repetitions of the same experiment.

Figure 9. Experimental and simulated expansion-time behavior for a coating of thickness $2000 \mu \mathrm{m}$. Exp3 and 4 refers to repetitions of the same experiment.

Figure 10. Simulated and experimental temperatures for an experiment with a coating thickness of $1200 \mu \mathrm{m}$. (TOP) Backside insulation temperature, steel temperature, calculated surface temperature, and measured gas temperature. (BOTTOM) Temperatures inside the char layer.

Figure 11. Simulated and experimental temperatures for an experiment with a coating thickness of $2000 \mu \mathrm{m}$. (TOP) Backside insulation temperature, steel temperature, calculated surface temperature, and measured gas temperature. (BOTTOM) Temperatures inside the char layer.

Figure 12. Simulated changes by varying the adjustable parameters, $E_{a}, k_{0}, d_{\epsilon, \text { carb,char }}, d_{\epsilon, \text { residue, }}$ and $t_{63 \%}$. The values are reduced to $80 \%$ of the value given in Table 3. (TOP) Simulation of steel temperature. (BOTTOM) Simulation of temperatures $1 \mathrm{~cm}$ above the steel plate. For the steel temperature only the effect of changing $E_{a}$ and $k_{0}$ are clearly observed in the graphs. For the temperature inside the char, $t_{63 \%}$ and $E_{a}$ are the most clearly observable parameters. Changes form the other parameters are below $20{ }^{\circ} \mathrm{C}$. $\beta$ and $k_{300}$ does not affect the temperatures noticeably.

Figure 13. Parameter study where the mass of steel and gas temperature have been. The base case simulation with parameters from Table 3 is also shown. (TOP) Simulations of the steel temperature. (BOTTOM) simulations of temperatures $1 \mathrm{~cm}$ above the steel plate.

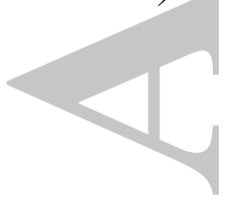


Figure 14. Thermal conductivity of chars as a function of temperature. Data from literature are presented for comparison. Wang et al..$^{39}$ (non-disclosed coating system) is based on image analysis of the char and validated against steel temperatures in a furnace. Bourbigot et al. ${ }^{14}$ (polypropylene system) determined on pre-heated samples, values obtained from modeling. Staggs ${ }^{40}$ (non-disclosed coating system) determined thermal conductivity from image analysis of char and thermal resistor network. Gomez-Mares et al. ${ }^{41}$ (epoxy system) used muffle furnace and hot disk. Thermal conductivity of the backside superwool insulation and the value of this work are also included. The thermal conductivity of air is also shown. The simulated value of this work refers to the arithmetic average temperature of the steel and char surface temperature.

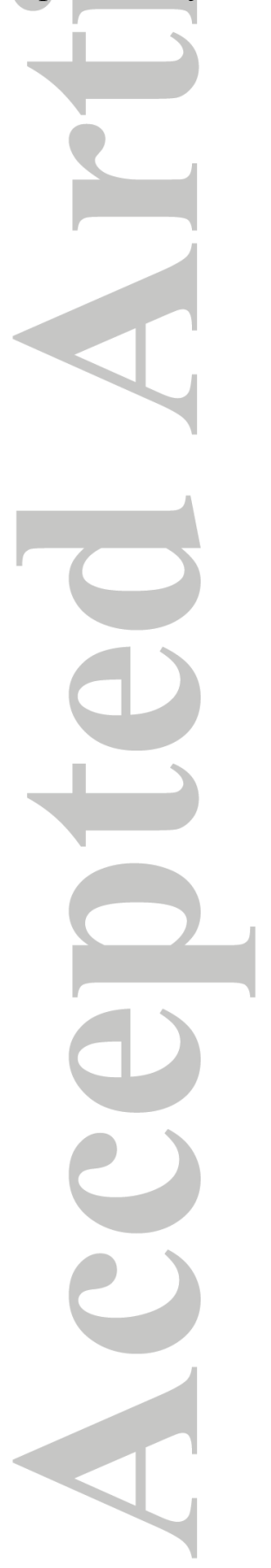




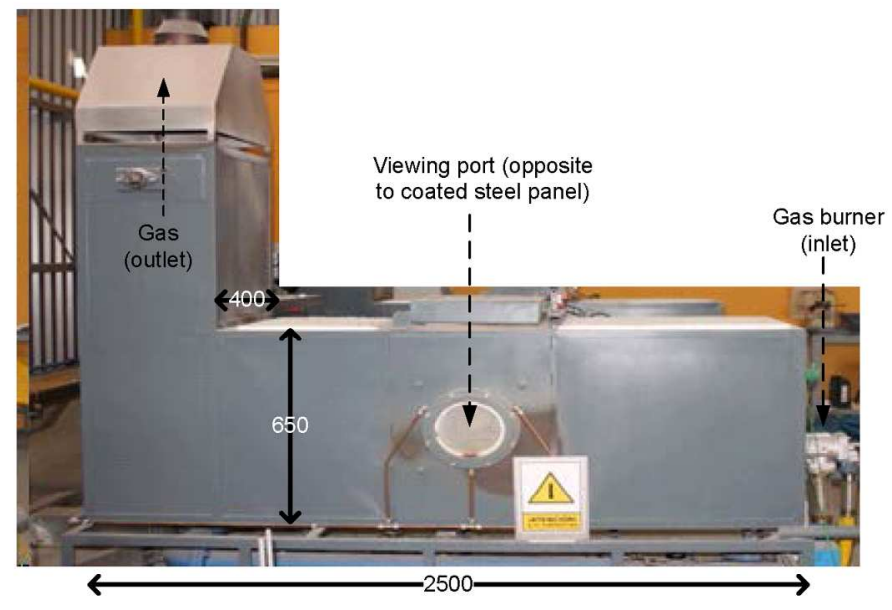

Figure 1. Photo of furnace with dimensions in $\mathrm{mm}$. The coated steel substrate (cannot be seen) is inserted in a vertical position opposite to the viewing port. Arrows indicate inner dimensions. $210 \times 297 \mathrm{~mm}(200 \times 200 \mathrm{DPI})$

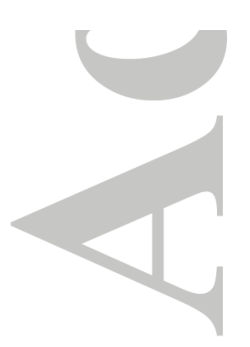

AIChE Journal

This article is protected by copyright. All rights reserved. 


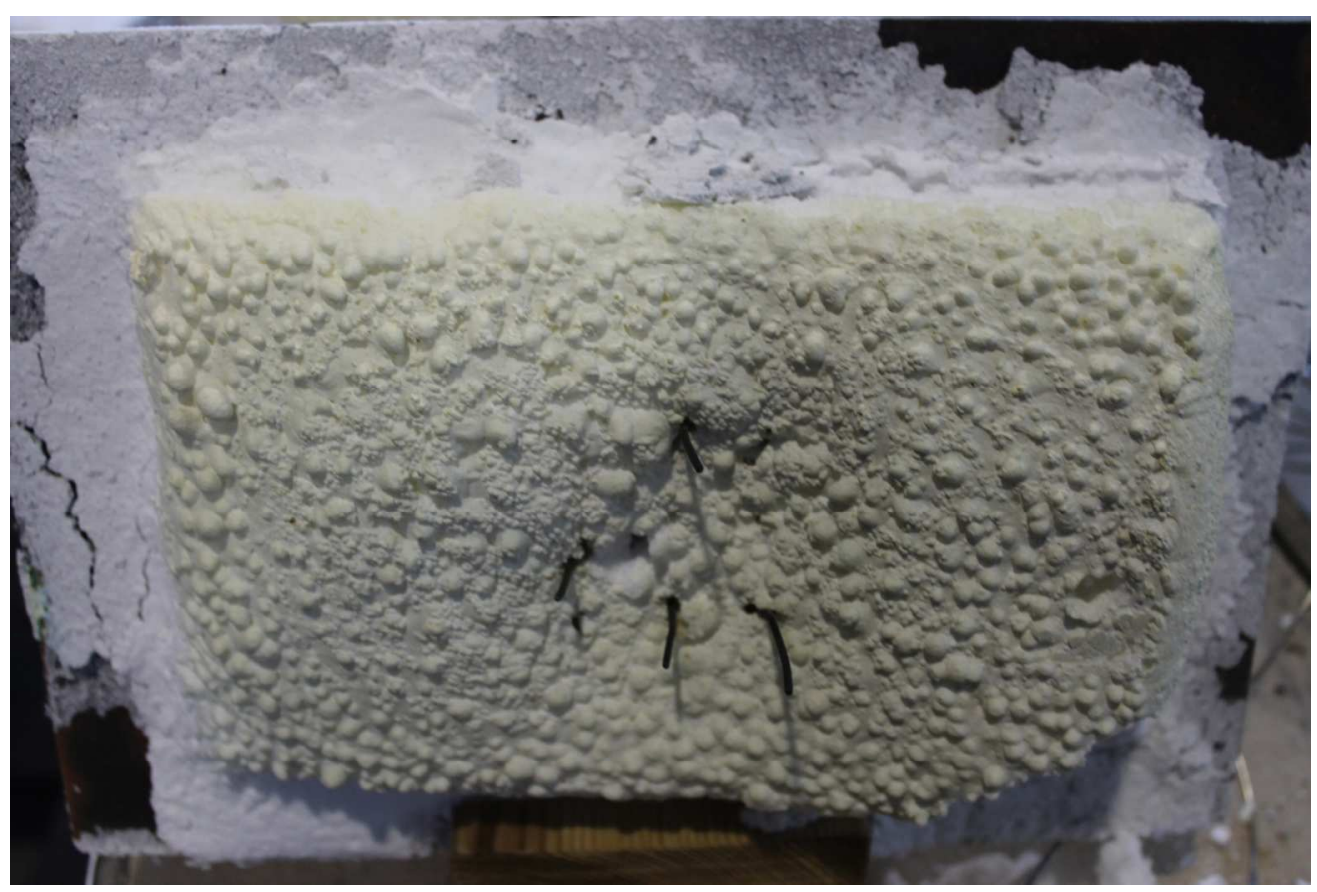

Figure 4. Photo of expanded char after 3 hours of heating in the furnace. The five uncovered metal thermocouples, placed above the char, can be seen close to the center of the char surface. The thermocouples already covered cannot be seen.

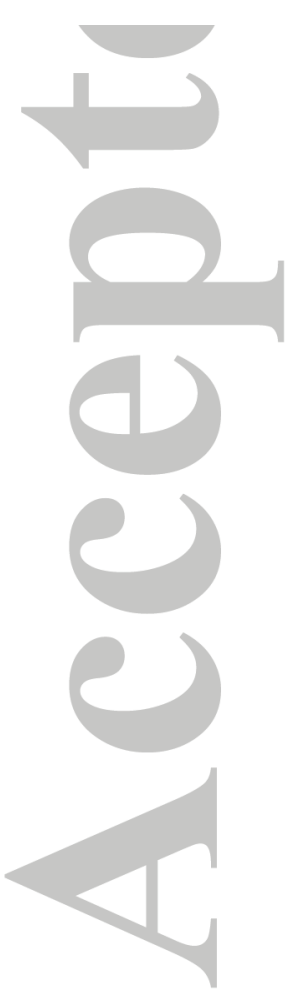

$175 \times 117 \mathrm{~mm}(220 \times 220$ DPI $)$ 


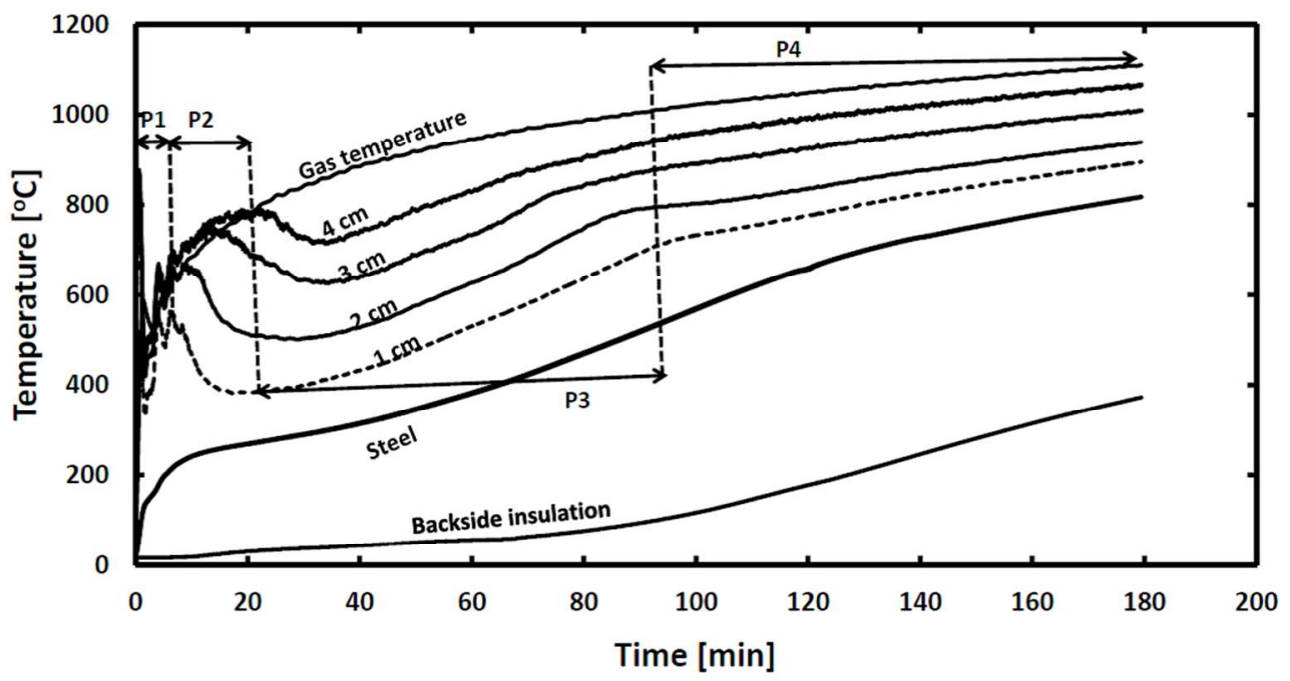

Figure 5. Measured temperatures for an experiment with a $1200 \mu \mathrm{m}$ thick intumescent coating. For the thermocouple placed $1 \mathrm{~cm}$ above the steel substrate, the temperature-time curve is divided into four time periods, termed P1-4. Temperatures of the gas, the backside insulation, the steel substrate and various positions above the steel substrate are also shown.

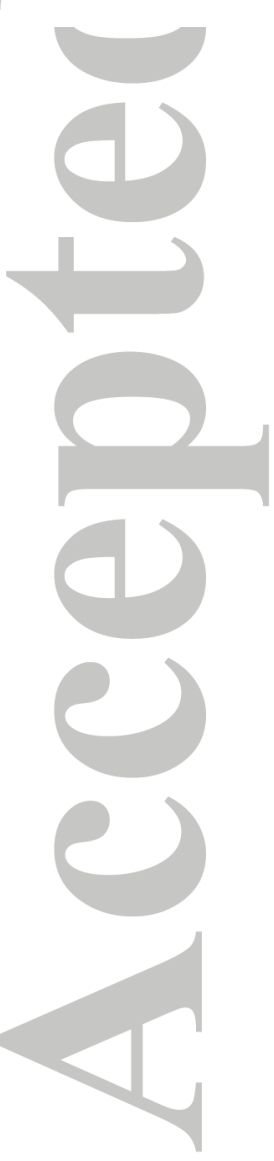
$300 \times 154 \mathrm{~mm}(96 \times 96 \mathrm{DPI})$ 


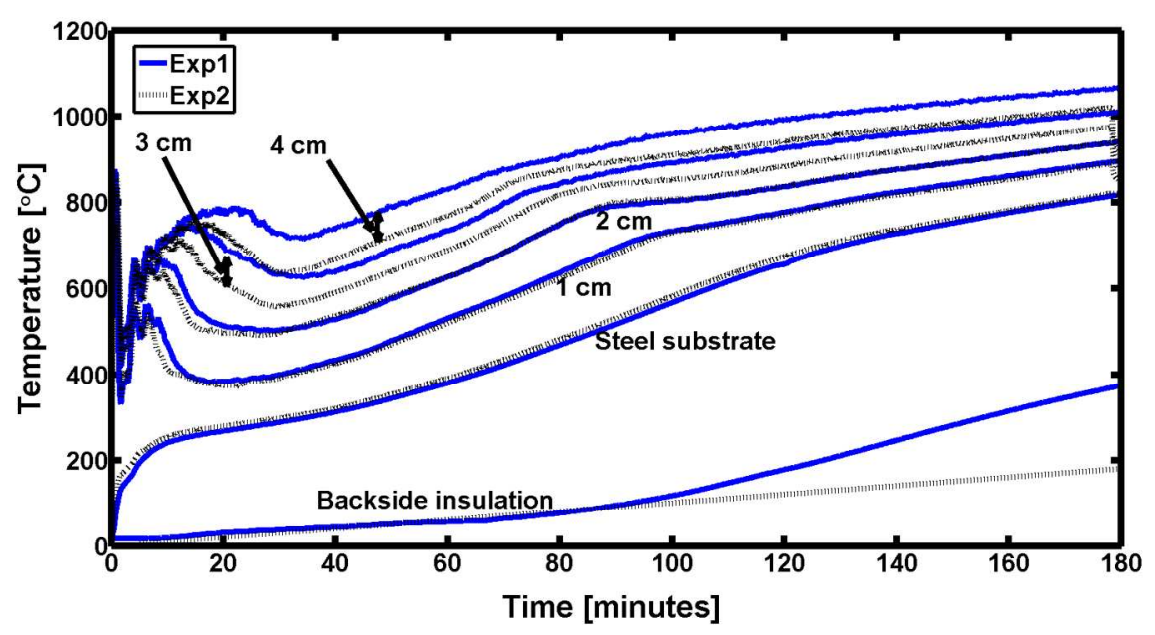

Figure 6. Example of the repeatability of experiments conducted in the furnace. The figure shows a comparison of temperatures for the two experiments (referred to as exp1 and 2) employing a coating thickness of $1200 \mu \mathrm{m}$.

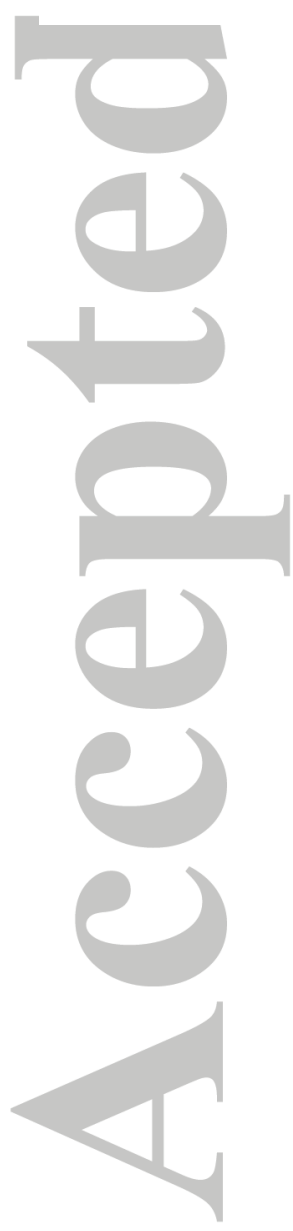
$508 \times 247 \mathrm{~mm}(96 \times 96 \mathrm{DPI})$ 


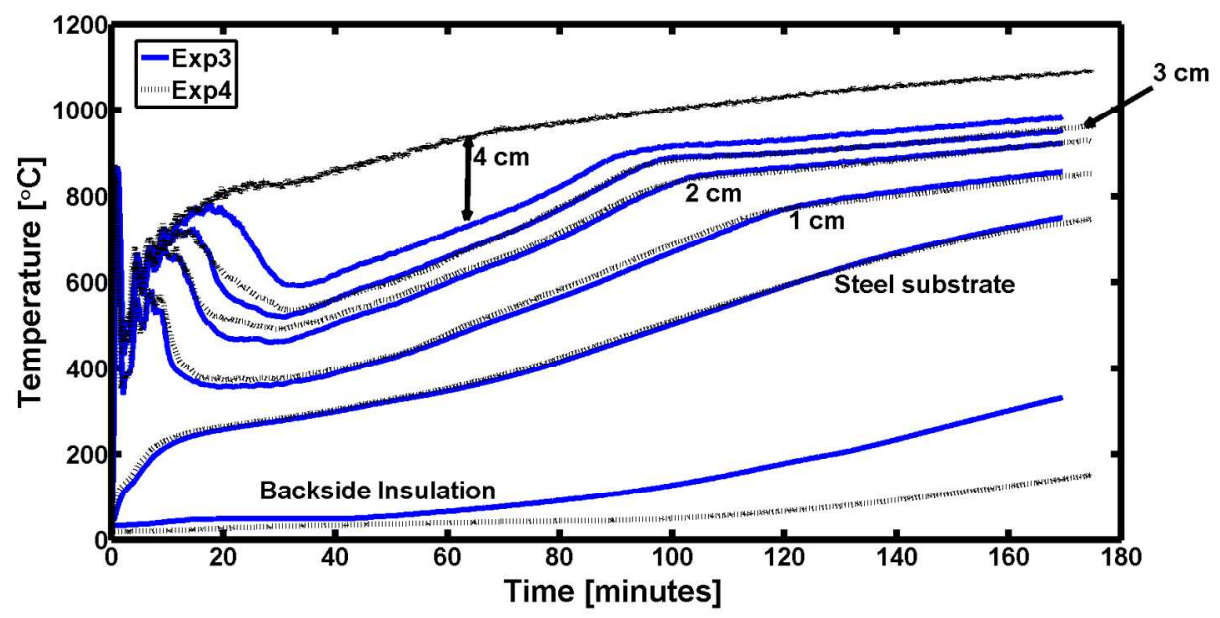

Figure 7. Example of the repeatability of experiments conducted in the furnace. The figure shows a comparison of temperatures for the two experiments (referred to as exp3 and 4) employing a coating thickness of $2000 \mu \mathrm{m}$.

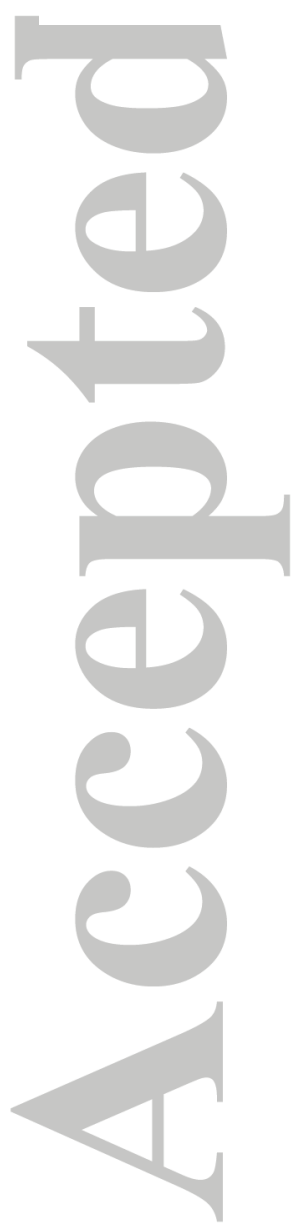
$508 \times 247 \mathrm{~mm}(96 \times 96 \mathrm{DPI})$ 


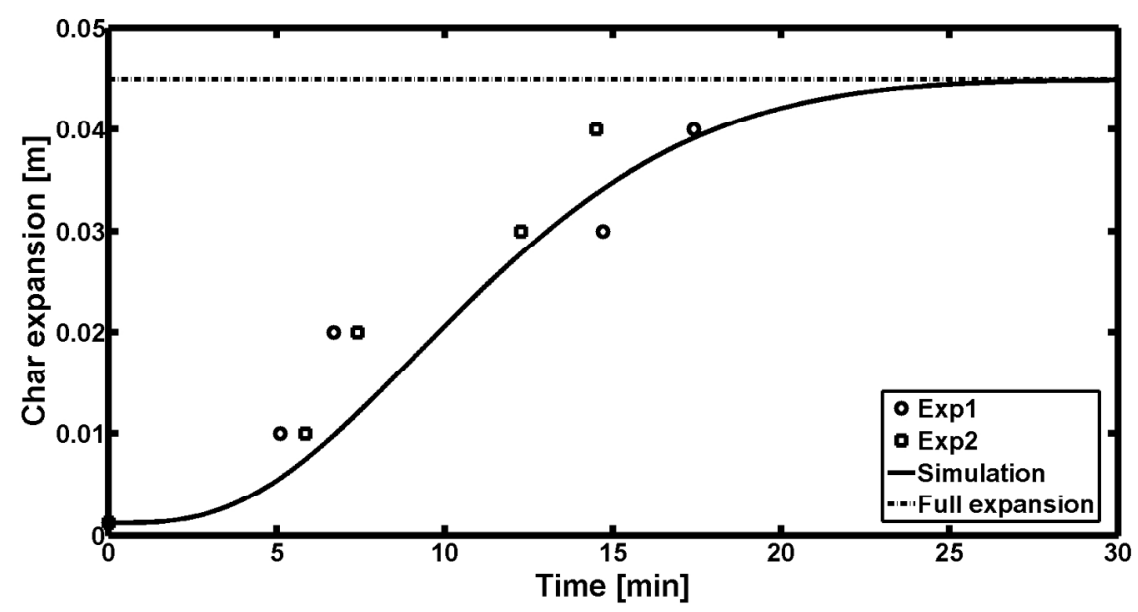

Figure 8. Experimental and simulated expansion-time behavior for a coating of thickness $1200 \mu \mathrm{m}$. Exp1 and 2 refers to repetitions of the same experiment.

$508 \times 243 \mathrm{~mm}(96 \times 96 \mathrm{DPI})$

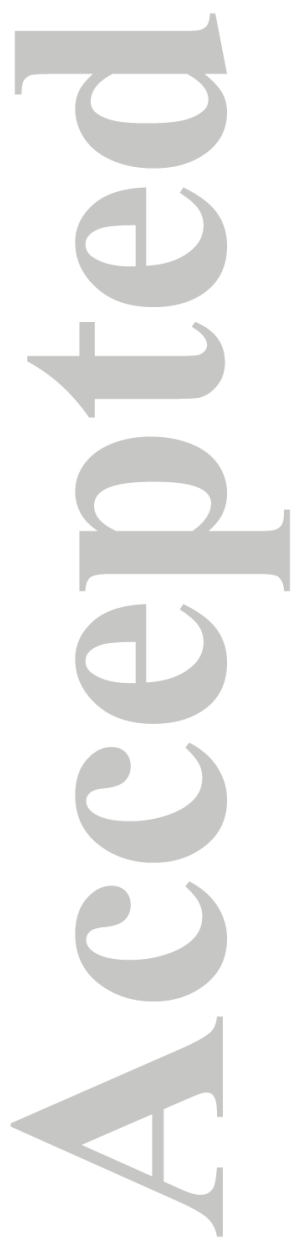




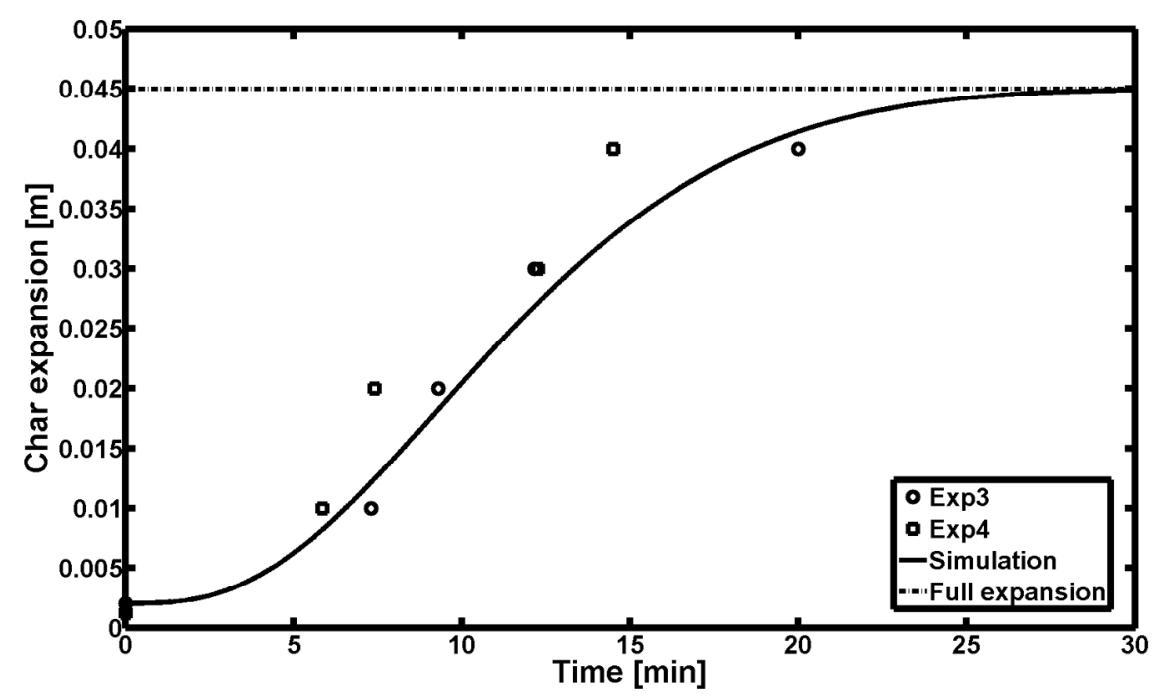

Figure 9. Experimental and simulated expansion-time behavior for a coating of thickness $2000 \mu \mathrm{m}$. Exp3 and 4 refers to repetitions of the same experiment.

$508 \times 287 \mathrm{~mm}(96 \times 96 \mathrm{DPI})$ 

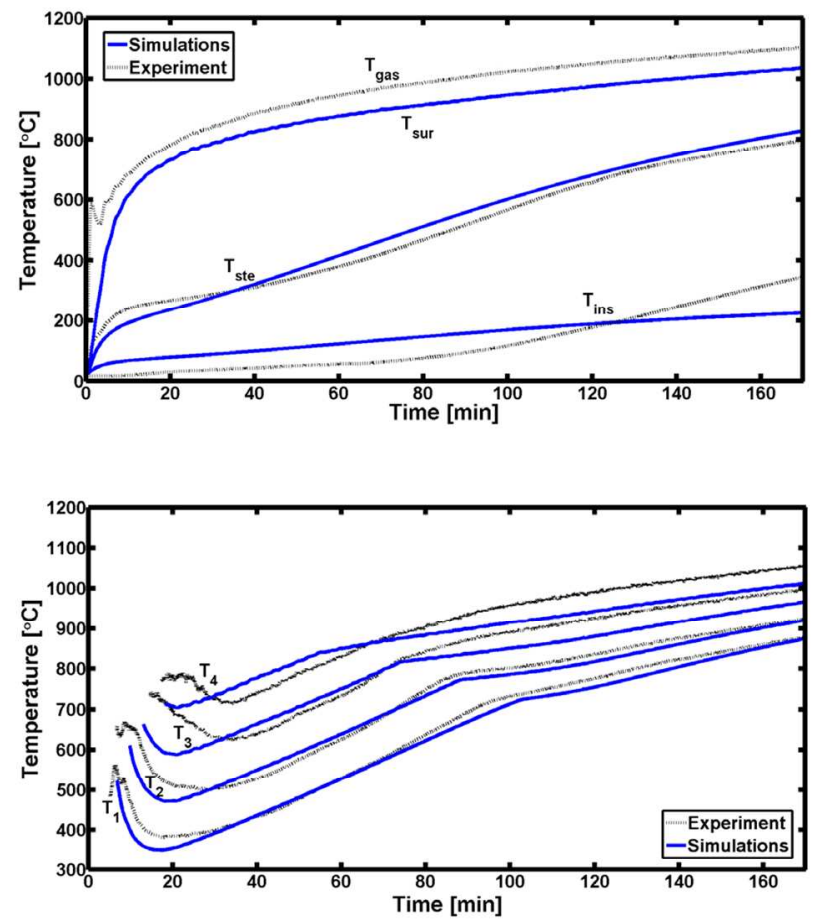

Figure 10. Simulated and experimental temperatures for an experiment with a coating thickness of 1200 $\mu \mathrm{m}$. (TOP) Backside insulation temperature, steel temperature, calculated surface temperature, and measured gas temperature. (BOTTOM) Temperatures inside the char layer.

$210 \times 297 \mathrm{~mm}(150 \times 150 \mathrm{DPI})$

\section{AIChE Journal}

This article is protected by copyright. All rights reserved. 

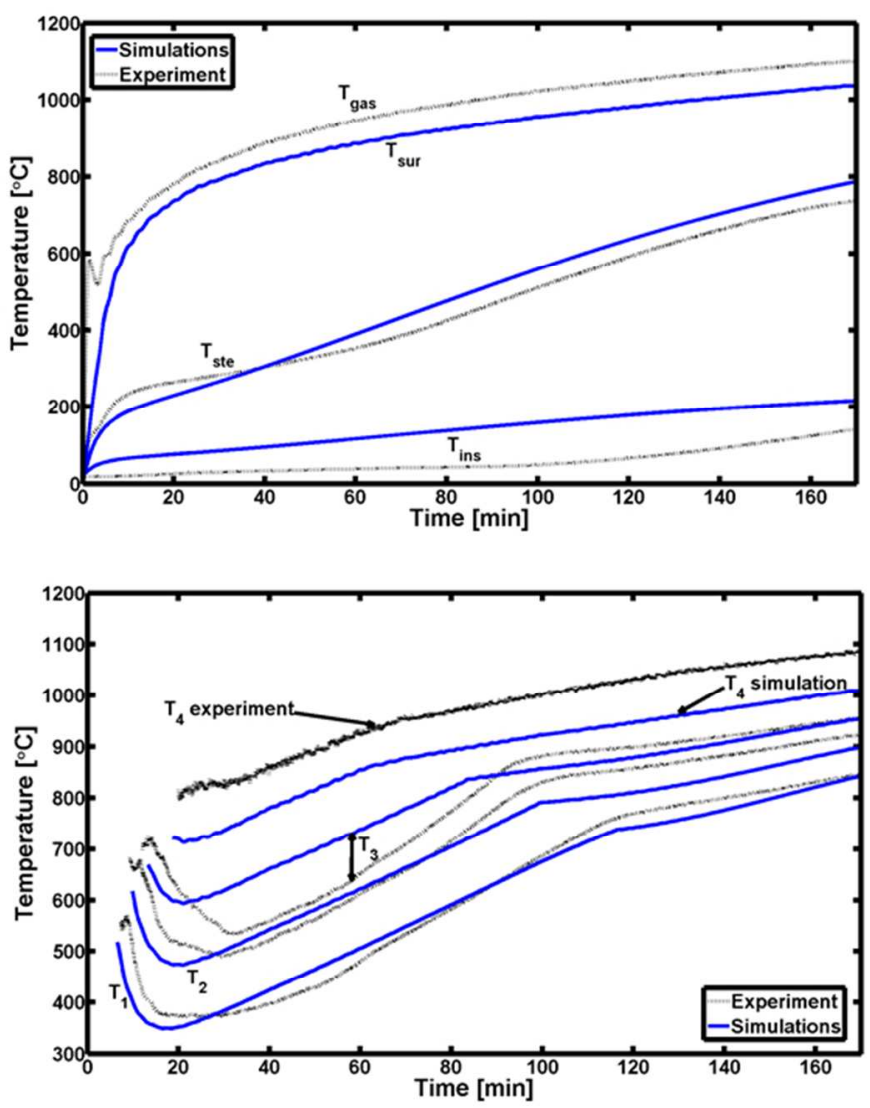

Figure 11. Simulated and experimental temperatures for an experiment with a coating thickness of 2000 $\mu \mathrm{m}$. (TOP) Backside insulation temperature, steel temperature, calculated surface temperature, and measured gas temperature. (BOTTOM) Temperatures inside the char layer.

$$
215 \times 266 \mathrm{~mm}(96 \times 96 \mathrm{DPI})
$$

\section{AIChE Journal}

This article is protected by copyright. All rights reserved. 

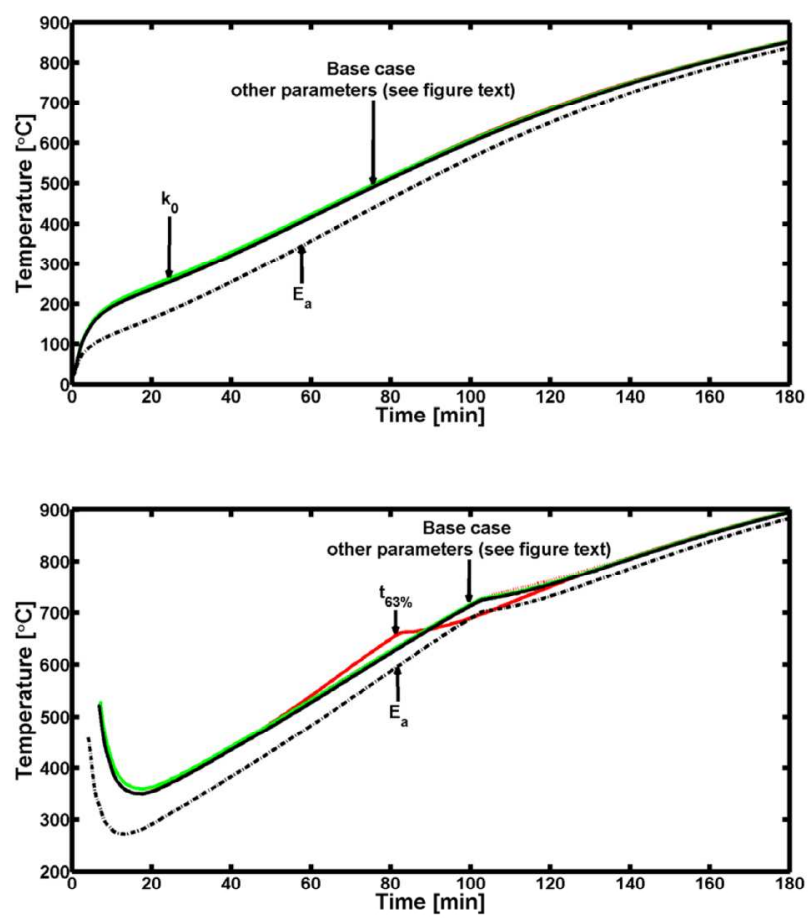

Figure 12 . Simulated changes by varying the adjustable parameters, $E_{a}, k_{0}, d_{\epsilon, \text { carb,char, }} d_{\epsilon, \text { residue, }}$ and $t_{63 \%}$. The values are reduced to $80 \%$ of the value given in Table 3. (TOP) Simulation of steel temperature. (BOTTOM) Simulation of temperatures $1 \mathrm{~cm}$ above the steel plate. For the steel temperature only the effect of changing $E_{a}$ and $k_{0}$ are clearly observed in the graphs. For the temperature inside the char, $t_{63 \%}$ and $E_{a}$ are the most clearly observable parameters. Changes form the other parameters are below $20{ }^{\circ} \mathrm{C}$. $210 \times 297 \mathrm{~mm}(200 \times 200 \mathrm{DPI})$

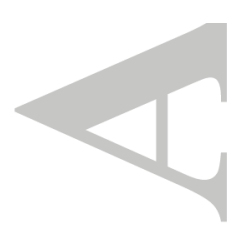

AlChE Journal

This article is protected by copyright. All rights reserved. 

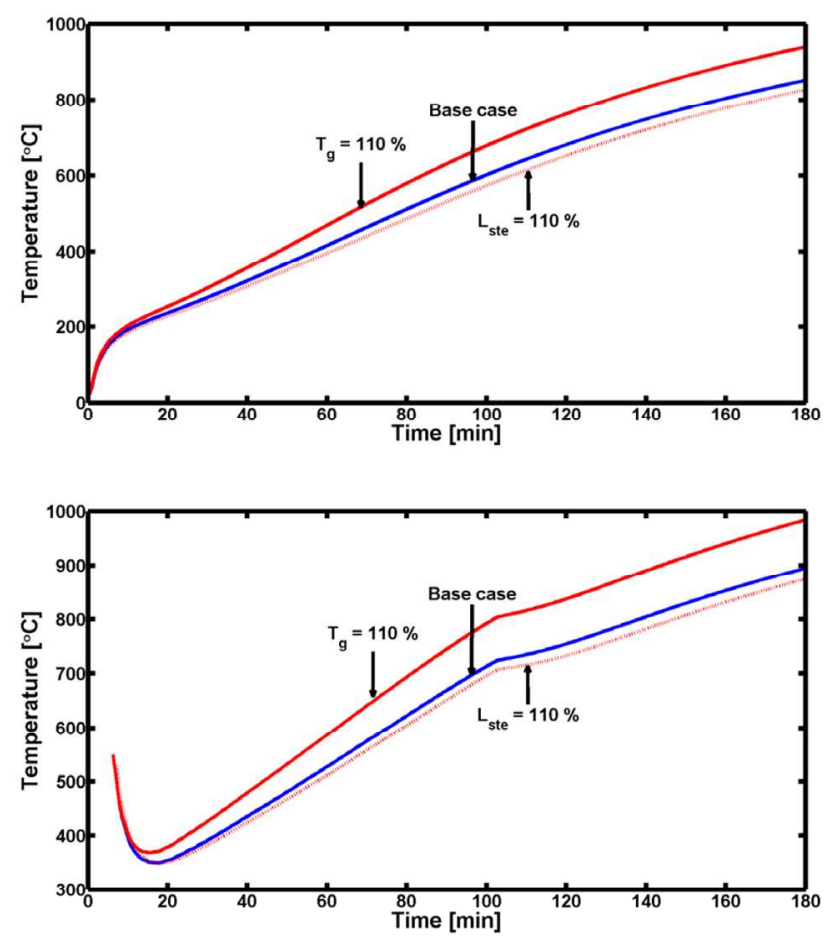

Figure 13. Parameter study where the mass of steel and gas temperature have been. The base case simulation with parameters from Table 3 is also shown. (TOP) Simulations of the steel temperature. (BOTTOM) simulations of temperatures $1 \mathrm{~cm}$ above the steel plate. $210 \times 297 \mathrm{~mm}(200 \times 200 \mathrm{DPI})$

\section{AIChE Journal}

This article is protected by copyright. All rights reserved. 


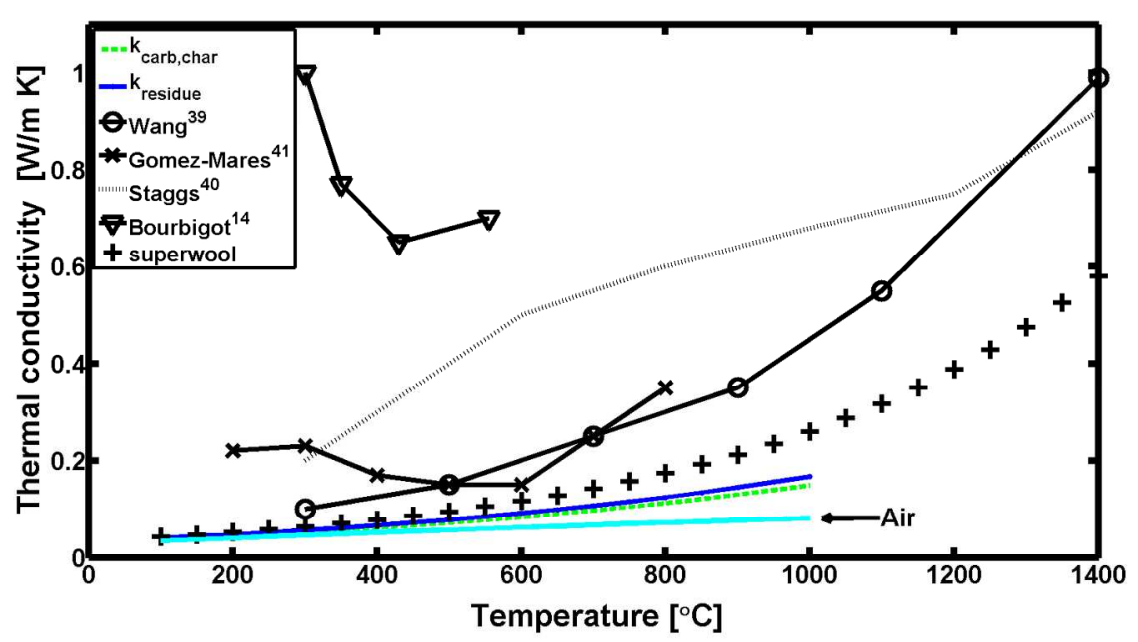

Figure 14. Thermal conductivity of chars as a function of temperature. Data from literature are presented for comparison. Wang et al. ${ }^{39}$ (non-disclosed coating system) is based on image analysis of the char and validated against steel temperatures in a furnace. Bourbigot et al. ${ }^{14}$ (polypropylene system) determined on pre-heated samples, values obtained from modeling. Staggs ${ }^{40}$ (non-disclosed coating system) determined thermal conductivity from image analysis of char and thermal resistor network. Gomez-Mares et al. ${ }^{41}$ (epoxy system) used muffle furnace and hot disk. Thermal conductivity of the backside superwool insulation and the value of this work are also included. The thermal conductivity of air is also shown. The simulated value of this work refers to the arithmetic average temperature of the steel and char surface temperature.

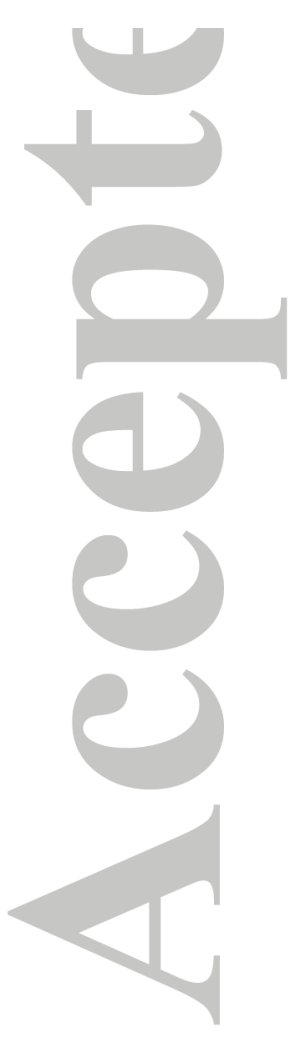

$$
508 \times 255 \mathrm{~mm}(96 \times 96 \mathrm{DPI})
$$


Table 1. Recent mathematical models of intumescent coatings with year of publication and equipment and time span used when validating the models. Other details can be found in Shi and Chew ${ }^{4}$.

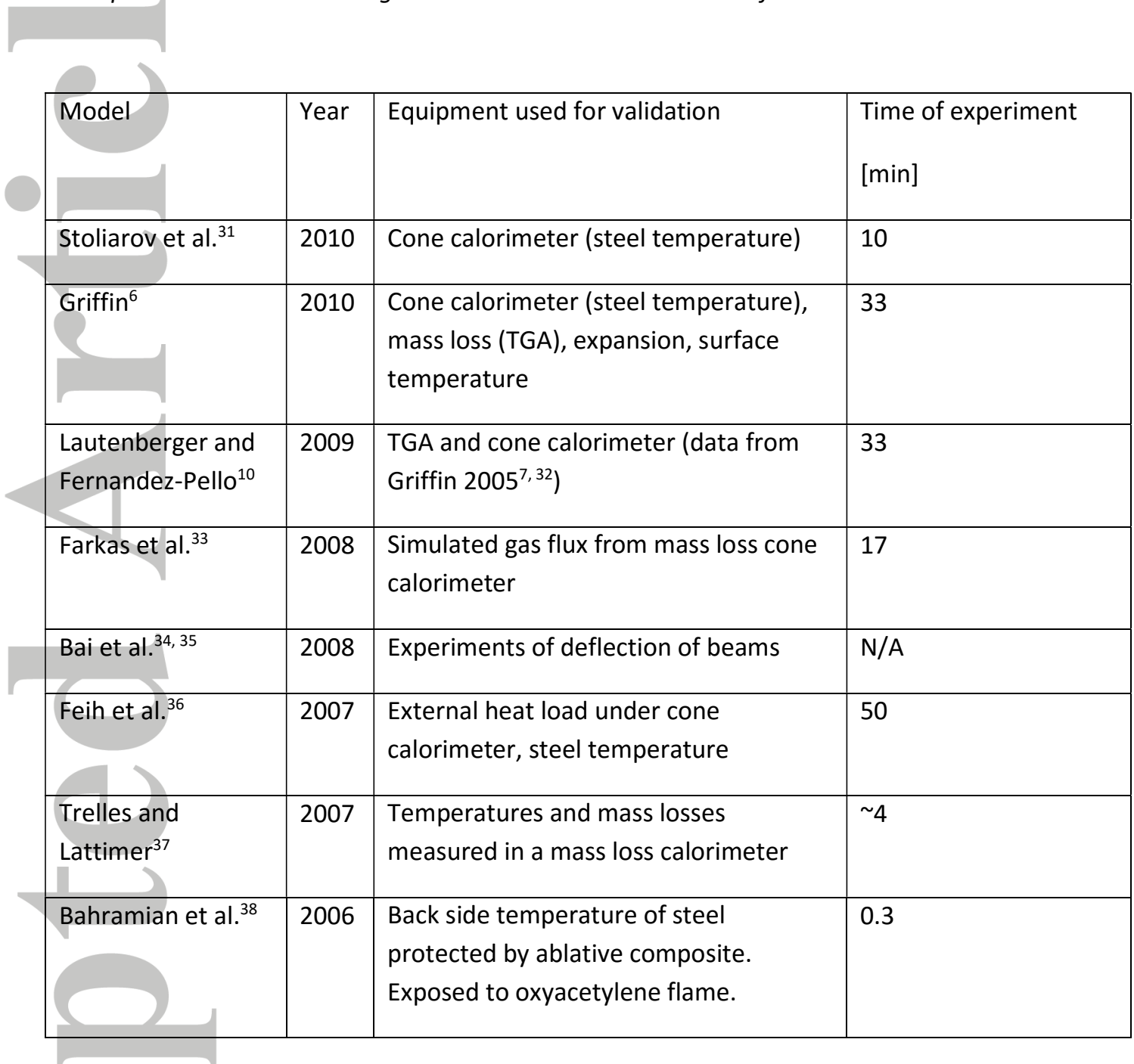

AIChE Journal

This article is protected by copyright. All rights reserved. 
Table 2. List of input parameters to simulations. Reference to an equation number is provided where the parameter is calculated using an equation or correlation.

\begin{tabular}{|c|c|c|c|}
\hline Parameter & Value & Unit & Reference/note \\
\hline $\begin{array}{l}\beta \text { - empirical constant in } \\
\text { temperature dependency of } \\
\text { thermal conductivity }\end{array}$ & 1 & - & Palankovski ${ }^{25}$ \\
\hline$\rho_{\text {ste }}-$ Density of steel & 7858 & $\mathrm{~kg} \cdot \mathrm{m}^{-3}$ & Incropera and De Witt ${ }^{23}$ \\
\hline$C_{p, s t e}-$ Heat capacity of the steel & Eq. (14) & $\mathrm{J} \cdot \mathrm{K}^{-1} \cdot \mathrm{kg}^{-1}$ & Incropera and De Witt ${ }^{23}$ \\
\hline $\begin{array}{l}\text { k } 300-\text { Thermal conductivity of } \\
\text { solid at } 300 \mathrm{~K}\end{array}$ & 1.38 & $\mathrm{~W} \cdot \mathrm{m}^{-1} \cdot \mathrm{K}^{-1}$ & Palankovski ${ }^{25}$ \\
\hline $\begin{array}{l}\mathrm{k}_{\text {ins }} \text { - Thermal conductivity of } \\
\text { backside insulation }\end{array}$ & Eq. (13) & $\mathrm{W}^{-1} \cdot \mathrm{m}^{-1} \cdot \mathrm{K}^{-1}$ & From supplier product sheet ${ }^{22}$ \\
\hline $\mathrm{h}$ - heat transfer number & 34 & $\mathrm{~W}^{-1} \cdot \mathrm{m}^{-2}$ & $\begin{array}{l}\text { Average value based on } \\
\text { measurements }\end{array}$ \\
\hline
\end{tabular}

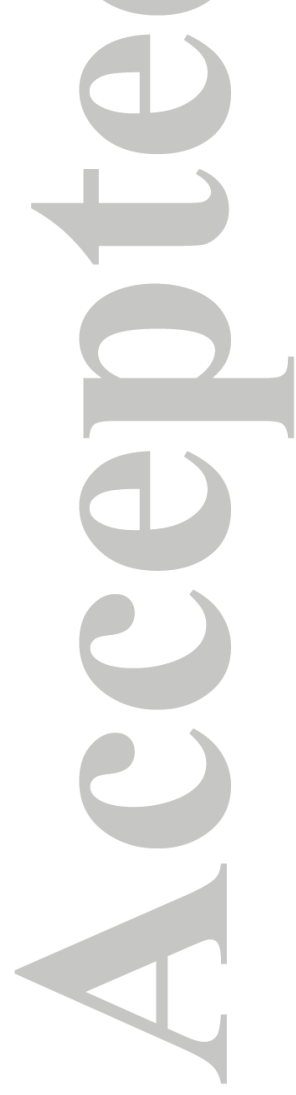

AlChE Journal

This article is protected by copyright. All rights reserved. 


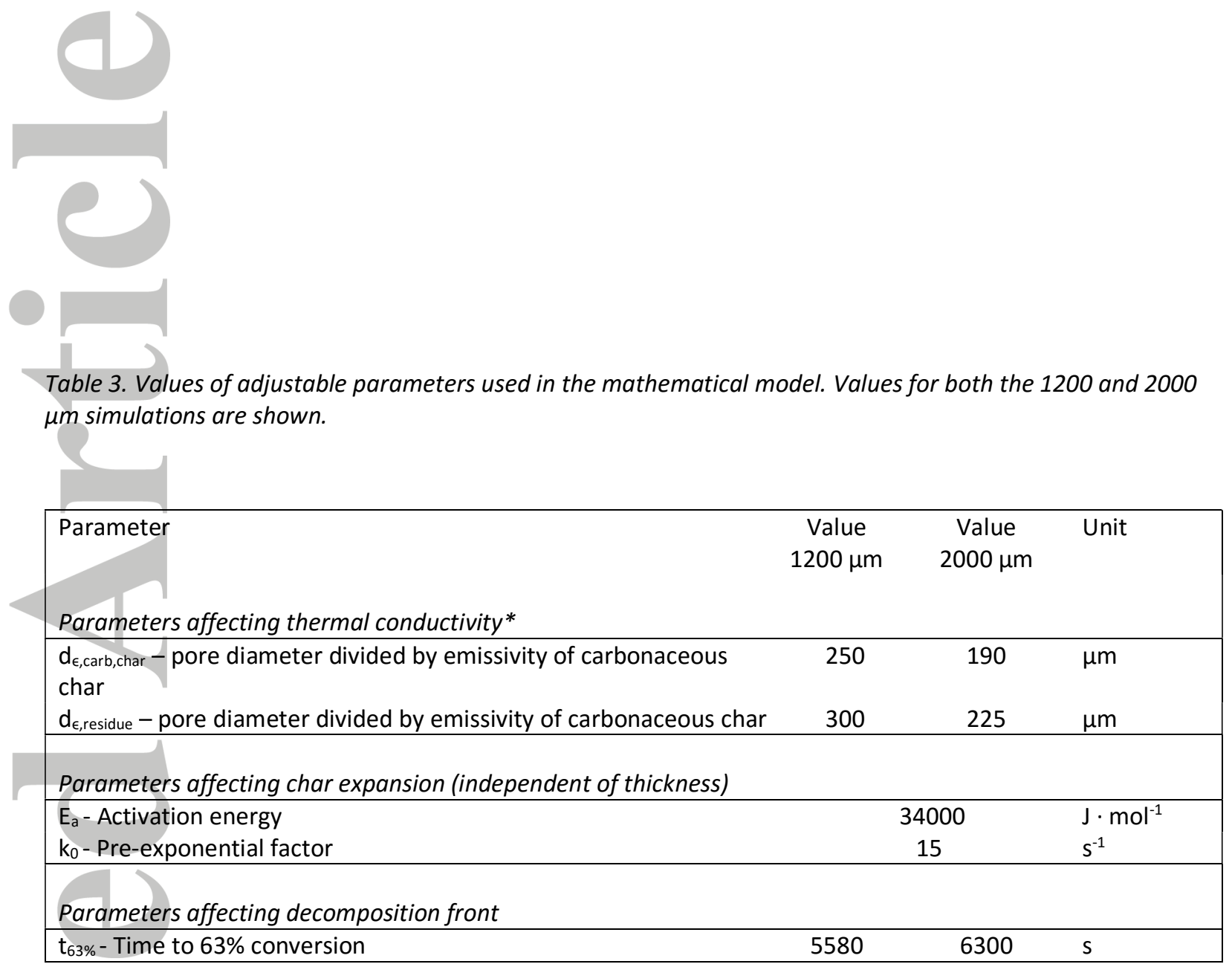

*The sensitivity analysis performed shows that the parameters related to thermal conductivity are of little influence on the results.

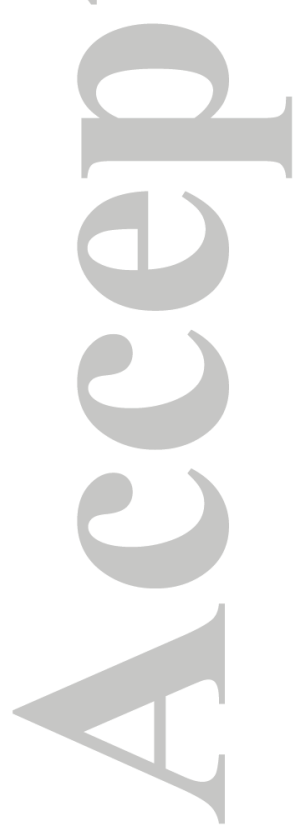

AIChE Journal

This article is protected by copyright. All rights reserved. 